\title{
Prophylaxe der Migräne mit monoklonalen Antikörpern gegen CGRP oder den CGRP-Rezeptor
}

\author{
Ergänzung der Leitlinie 030/057 Therapie der Migräneattacke und Prophylaxe der \\ Migräne
}

Entwicklungsstufe: S1

Federführend

Prof. Dr. med. Hans-Christoph Diener, Essen

Prof. Dr. med. Arne May, Hamburg

Herausgegeben von der Kommission Leitlinien der Deut-

schen Gesellschaft für Neurologie (DGN) in Zusammenarbeit

mit der Deutschen Migräne- und Kopfschmerzgesellschaft

(DMKG)

Version

Stand: 30. August 2019

Gültig bis: 1. September 2022

Kapitel: Kopfschmerzen und andere Schmerzen

\section{Zitierhinweis}

Diener HC, May A. et al. Prophylaxe der Migräne mit monoklonalen Antikörpern gegen CGRP oder den CGRP-Rezeptor, Ergänzung der S1-Leitlinie Therapie der Migräneattacke und Prophylaxe der Migräne, 2019, in: Deutsche Gesellschaft für Neurologie (Hrsg.), Leitlinien für Diagnostik und Therapie in der Neurologie. Online: www.dgn.org/leitlinien (abgerufen am TT.MM.JJJJ)

\section{Empfehlungen der DGN und DMKG}

Autoren

Hans-Christoph Diener, Stefanie Förderreuther, Charly Gaul, Florian Giese, Till Hamann, Dagny Holle-Lee, Tim P. Jürgens, Katharina Kamm, Torsten Kraya, Christian Lampl, Arne May, Uwe Reuter, Armin Scheffler, Peer Tfelt-Hansen

Bibliografie

DOI https://doi.org/10.1055/a-1083-7437

Nervenheilkunde 2020; 39: 2-24

(c) Georg Thieme Verlag KG Stuttgart · New York

ISSN 1865-1739

Korrespondenzadresse

hans.diener@uk-essen.de

www.dgn.org, www.awmf.org

\section{ZUSAMMENFASSUNG}

Monoklonale Antikörper gegen den Calcitonin Gene-Related Peptide (CGRP)-Rezeptor (Erenumab) oder gegen CGRP (Eptinezumab, Fremanezumab, Galcanezumab) sind neue Substanzen zur prophylaktischen Behandlung der Migräne. Sie stellen eine Erweiterung der therapeutischen Optionen in der Migräneprophylaxe dar. In Zulassungsstudien wurden die Wirksamkeit und die gute Verträglichkeit dieser spezifischen Substanzen bei Patienten mit episodischer und chronischer Migräne nachgewiesen. Die folgende Empfehlung präsentiert eine Zusammenfassung der Daten aus den Zulassungsstudien.
Weiterhin werden Empfehlungen zur gezielten Patientenauswahl sowie zur Beurteilung des Therapieerfolgs und der Dauer der Behandlung gegeben. Abschließend werden mögliche Anwendungseinschränkungen für diese neue Substanzgruppe diskutiert.

\section{ABSTRACT}

Monoclonal antibodies against the calcitonin gene-related peptide (CGRP) receptor (erenumab) or against CGRP (eptinezumab, fremanezumab, galcanezumab) are new substances for the preventive treatment of migraine. They represent an extension of the therapeutic options which already exist in migraine prevention. In registration studies, the efficacy and good tolerability of these specific substances have been demonstrated in patients with episodic and chronic migraine. The following treatment recommendation presents a summary of the pivotal studies. Recommendations are given for the targeted selection of patients as well as for the evaluation of therapeutic success and the duration of treatment. Finally, possible restrictions in the use of this new substance group are discussed. 
Inhalt

1. Fragestellungen

2. Empfehlungen

3. Einleitung

4. Calcitonin Gene-Related Peptide (CGRP) und Migräne

5. Erenumab zur Prophylaxe der episodischen Migräne

6. Fremanezumab zur Prophylaxe der episodischen Migräne

7. Galcanezumab zur Prophylaxe der episodischen Migräne

8. Eptinezumab zur Prophylaxe der episodischen Migräne

9. Studien zur Prophylaxe der chronischen Migräne

10. Erenumab zur Prophylaxe der chronischen Migräne

11. Fremanezumab zur Prophylaxe der chronischen Migräne

12. Galcanezumab zur Prophylaxe der chronischen Migräne

13. Eptinezumab zur Prophylaxe der chronischen Migräne

14. Leitlinien zum Einsatz von monoklonalen Antikörpern zur Prophylaxe der Migräne

15. Vergleich der Wirksamkeit der monoklonalen Antikörper bei der episodischen und der chronischen Migräne

16. Besondere Populationen und Fragestellungen

17. Redaktionskomitee

18. Leitlinienreport

19. Literatur

\section{Fragestellungen}

1. Sind monoklonale Antikörper (monoclonal antibodies = MOAB) gegen CGRP oder den CGRP-Rezeptor bei der episodischen Migräne prophylaktisch wirksam?

2. Sind monoklonale Antikörper gegen CGRP oder den CGRP-Rezeptor bei der chronischen Migräne prophylaktisch wirksam?

3. Welche Patienten sollten einen monoklonalen Antikörper zur Migräneprophylaxe bekommen?

4. Wie wird der Therapieerfolg evaluiert?

5. Wie lange sollte die Therapie erfolgen?

6. Welche Gegenanzeigen und Warnhinweise bestehen für den Einsatz von monoklonalen Antikörpern?

7. Ist es sinnvoll, bei Nichtansprechen der Therapie mit einem CGRP-Antagonisten auf einen CGRP-Rezeptorantagonisten zu wechseln und umgekehrt?

\section{Empfehlungen}

1. Sind monoklonale Antikörper (monoclonal antibodies = MOAB) gegen CGRP oder den CGRP-Rezeptor bei der episodischen Migräne prophylaktisch wirksam?

Die monoklonalen Antikörper gegen CGRP (Eptinezumab, Fremanezumab und Galcanezumab) oder gegen den CGRP-Rezeptor (Er- enumab) sind bei der prophylaktischen Therapie der episodischen Migräne einer Behandlung mit Placebo überlegen. Die Reduktion der Migränetage pro Monat bei der episodischen Migräne beträgt zwischen 2,9 und 4,7 Tagen. Die 50\%-Responderrate nach 3-6 Monaten liegt dabei zwischen $30 \%$ und 62\%. Die 50\%-Responderraten für Placebo liegen zwischen 17 und 38\%. Die Wirksamkeit kann innerhalb von 4-8 Wochen evaluiert werden. Ein direkter Vergleich der monoklonalen Antikörper untereinander ist ebenso wenig möglich wie ein Vergleich mit den bisher zur Verfügung stehenden Migräneprophylaktika.

2. Sind monoklonale Antikörper gegen CGRP oder den CGRP-Rezeptor bei der chronischen Migräne prophylaktisch wirksam?

Die monoklonalen Antikörper gegen CGRP (Eptinezumab, Fremanezumab und Galcanezumab) oder gegen den CGRP-Rezeptor (Erenumab) sind in der prophylaktischen Therapie der chronischen Migräne einer Behandlung mit Placebo überlegen. Die Reduktion der Migränetage pro Monat liegt für die chronische Migräne zwischen 4,3 und 6,6 Tagen. Die Responderrate nach 3 Monaten liegt zwischen 27 und 57\%. Die 50 \%-Responderraten für Placebo liegen zwischen 15 und $40 \%$. Die Wirksamkeit konnte auch für Patienten mit Kopfschmerzen durch Übergebrauch von Schmerz- oder Migränemitteln (medication overuse headache $=\mathrm{MOH}$ ) gezeigt werden. Ein direkter Vergleich der monoklonalen Antikörper untereinander ist ebenso wenig möglich wie ein Vergleich mit den bisher zur Verfügung stehenden Migräneprophylaktika.

3. Welche Patienten sollten einen monoklonalen Antikörper zur Migräneprophylaxe bekommen?

Die Zulassung besteht für die Behandlung einer Migräne mit mindestens 4 Migränetagen/Monat. Nach dem Beschluss des Gemeinsamen Bundesausschusses (GBA) ist eine Verordnung bei Patienten mit episodischer Migräne möglich, wenn mindestens 5 Substanzen aus den 4 verfügbaren, zugelassenen medikamentösen pharmakologischen Gruppen wie Betablocker (Metoprolol oder Propranolol), Flunarizin, Topiramat, Valproinsäure oder Amitriptylin nicht wirksam waren, nicht vertragen wurden oder wenn gegen deren Einnahme Kontraindikationen oder Warnhinweise bestehen. Bezüglich Patienten mit chronischer Migräne wird empfohlen, dass diese zusätzlich nicht auf eine Therapie mit OnabotulinumtoxinA angesprochen haben.

\section{Wie wird der Therapieerfolg evaluiert?}

Bei der episodischen und chronischen Migräne ist ein Therapieerfolg definiert als eine Reduzierung der durchschnittlichen monatlichen Kopfschmerztage um 50 \% oder mehr im Vergleich zur Vorbehandlung über einen Zeitraum von mindestens 3 Monaten (Tagebuch-Dokumentation wird empfohlen) [1]. Alternative klinisch akzeptable Kriterien sind signifikante Verbesserungen von validierten, migränespezifischen, patientenbezogenen Outcome-Messungen wie:

- eine 30 \%ige Reduzierung des MIDAS-Scores für diejenigen mit Basiswerten über 20, 


\section{Prophylaxe der Migräne mit monoklonalen Antikörpern}

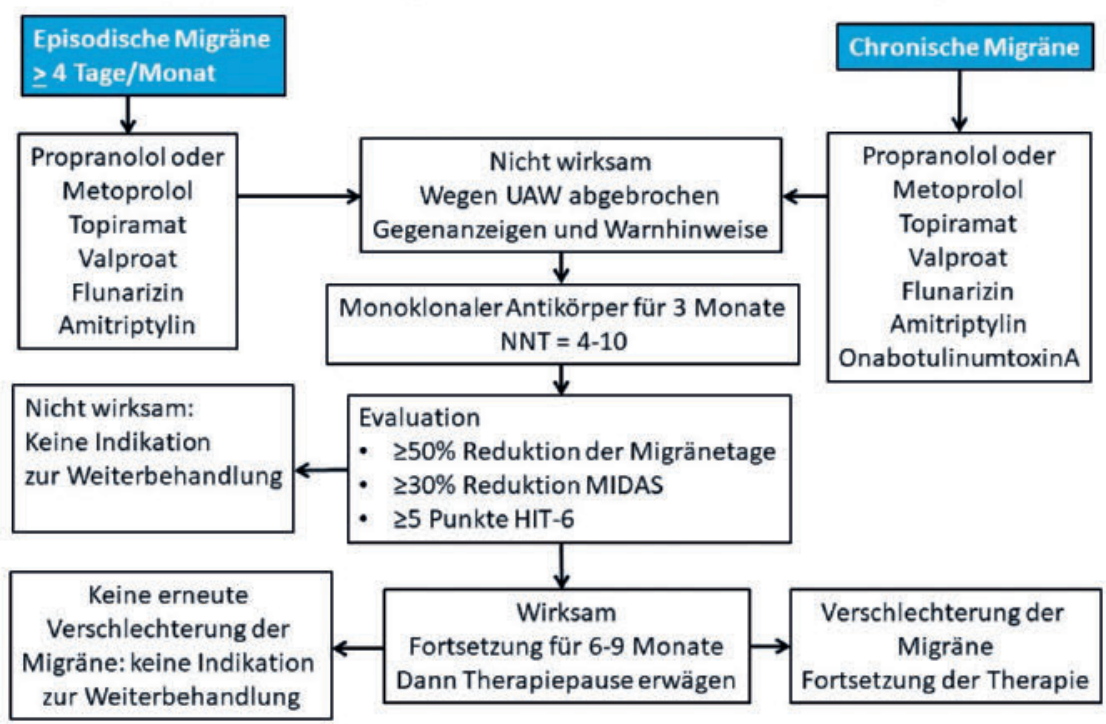

- Abb. 1 Flussdiagramm: Prophylaxe der Migräne mit monoklonalen Antikörpern

- Reduzierung der Punktzahl beim 6-Punkte-Headache-Impact-Test (HIT-6) [2] um mindestens 5 Punkte.

5. Wie lange sollte die Therapie erfolgen?

Die Therapie sollte zunächst für 3 Monate erfolgen. Wenn kein befriedigender Therapieeffekt besteht, wird die Therapie beendet. Bei Wirksamkeit der Therapie sollte nach 6-9 Monaten ein Auslassversuch unternommen werden, um zu überprüfen, ob die Therapie noch notwendig ist.

6. Welche Gegenanzeigen und Warnhinweise bestehen für den Einsatz von monoklonalen Antikörpern?

Monoklonale Antikörper gegen CGRP oder den CGRP-Rezeptor sollen bei Schwangeren und während der Stillzeit nicht eingesetzt werden. Sie sollten nicht eingesetzt werden bei Frauen, die keine oder keine ausreichende Kontrazeption betreiben. Weiterhin sollten sie vorsichtshalber nicht eingesetzt werden bei Patienten mit koronarer Herzerkrankung, ischämischem Insult, Subarachnoidalblutung oder peripherer arterieller Verschlusskrankheit. Für Kinder und Jugendliche gibt es bisher keine Informationen zur Verträglichkeit und Sicherheit. Monoklonale Antikörper sollten bis auf weiteres nicht bei Patienten mit entzündlichen Darmerkrankungen, COPD, pulmonaler Hypertension, M. Raynaud, Wundheilungsstörungen oder bei Transplantationsempfängern eingesetzt werden. Da die vorliegenden Studien bislang ausschließlich Patienten ohne relevante Vorerkrankungen eingeschlossen haben, sollte bei Patienten mit chronischen Vorerkrankungen zurückhaltend vorgegangen werden.
7. Ist es sinnvoll, bei Nichtansprechen der Therapie mit einem CGRP-Antagonisten auf einen CGRP-Rezeptorantagonisten zu wechseln und umgekehrt?

Zu dieser Frage gibt es keine Daten aus den randomisierten Studien oder Registern. Der Versuch einer Therapieumstellung scheint gerechtfertigt ( $\triangleright$ Abb. 1).

\section{Einleitung}

Patienten mit häufigen oder schweren Migräneattacken benötigen neben einer wirksamen Therapie der akuten Migräneattacke eine nicht medikamentöse und/oder medikamentöse Migräneprophylaxe [3]. Bisher standen hierfür nach den Leitlinien der Deutschen Gesellschaft für Neurologie und der Deutschen Migräne- und Kopfschmerzgesellschaft die Beta-Rezeptorenblocker Propranolol, Metoprolol und Bisoprolol, der Calciumantagonist Flunarizin, die Antikonvulsiva Valproinsäure und Topiramat sowie das trizyklische Antidepressivum Amitriptylin mit hohem Evidenzgrad zur Verfügung [3]. Nach einem Beschluss des GBA darf Valproinsäure zur Migränebehandlung nur noch von Fachärzten für Nervenheilkunde, Psychiatrie oder Neurologie verordnet werden (https://www.gba.de/downloads/39-261-3911/2019-08-06_AM-RL-VI-SN_Valproinsaeure-Migraeneprophylaxe.pdf). Über die Notwendigkeit zur konsequenten, sicheren Verhütung muss schriftlich aufgeklärt werden. Bei der chronischen Migräne sind Topiramat und OnabotulinumtoxinA wirksam. Die bisher eingesetzten Medikamente zur Migräneprophylaxe haben eine vergleichbare Wirkung. Als Zielkriterium wird laut den aktuellen Empfehlungen der Internationalen Kopfschmerzgesellschaft die $50 \%$-Responderrate herangezogen [4]. Diese beschreibt den Prozentsatz der Migränepatienten, bei 
denen es in der Regel nach 3-monatiger Therapie zu einer Reduktion der Migränetage/Monat um $\geq 50 \%$ vom Ausgangswert kommt. Die $50 \%$-Responderrate lag bisher zwischen $35 \%$ und $50 \%$, was bedeutet, dass es bei der Hälfte der Patienten unter einer Therapie nicht zu einer signifikanten Abnahme der Migränehäufigkeit kam. In diesen Fällen mussten dann häufig die einzelnen Medikamentengruppen konsekutiv und zum Teil additiv eingesetzt werden, um eine wirksame und verträgliche Therapie zu finden.

Die bisher verfügbaren Migräneprophylaktika sind bei vielen Patienten gut wirksam. Ein Problem der meisten bisherigen Migräneprophylaktika sind allerdings unerwünschte Arzneimittelwirkungen. Dies erklärt, warum Adhärenz und Persistenz gering sind [5]. Daher bestand ein hoher Bedarf, neue Migräneprophylaktika mit einem günstigeren Nebenwirkungsprofil zu entwickeln.

\section{Calcitonin Gene-Related Peptide (CGRP) und Migräne}

1990 identifizierten Goadsby und Edvinsson die wichtige Rolle von CGRP in der Pathophysiologie der Migräne [6, 7]. Sie untersuchten systematisch Neuropeptide in Blutproben der Vena jugularis während akuter Migräneattacken. Dabei fanden sie heraus, dass während Migräneattacken CGRP ausgeschüttet wurde und dass die CGRP-Konzentration abnahm, wenn die Attacke erfolgreich mit Sumatriptan behandelt wurde. Kurz danach wurde CGRP im Ganglion trigeminale des Menschen [8] sowie in den Wänden zerebraler Arterien nachgewiesen [7, 9]. In den folgenden Jahren identifizierten Goadsby und Edvinsson CGRP-Rezeptoren in den Wänden zerebraler Gefäße und Arterien der Dura, im trigemino-vaskulären System und in zentralen schmerzleitenden Strukturen [10]. CGRP ist ein potenter Vasodilatator [11]. CGRP-Rezeptoren finden sich darüber hinaus ubiquitär im Körper, unter anderem in der Darmmukosa und im respiratorischen Endothel. CGRP liegt in einer Alpha- und in einer Betaform vor, wobei für die Pathophysiologie und Therapie der Migräne nur die Alphaform relevant ist. Die Betaform von CGRP ist im enterischen System bedeutsam [12]. Zwischen den beiden Formen besteht eine Strukturanalogie von über $90 \%$.

Die Freisetzung von CGRP in den Gefäßwänden von Arterien der Dura und des Gehirns erfolgt über Synapsen des N. trigeminus. Die Freisetzung im Nervensystem erfolgt v. a. aus den trigeminalen C-Fasern, während Rezeptoren auf den trigeminalen A-delta-Fasern gefunden wurden. Die Ausschüttung von CGRP wird durch die Aktivierung von 5-HT- ${ }_{1 \mathrm{~B}}$ und 5-HT-1D-Rezeptoren gehemmt. An diesen Rezeptoren greifen beispielsweise die Triptane an.

Der endgültige Beweis, dass ein Eingriff in den CGRP-Kreislauf wirksam gegen Migräneattacken ist, war eine placebokontrollierte Studie von Olesen und Diener, in der ein CGRP-Antagonist signifikant wirksam Migräneattacken beendete [13].

4 monoklonale Antikörper - Eptinezumab, Erenumab, Fremanezumab und Galcanezumab - wurden umfangreichen klinischen Studien bei episodischer und chronischer Migräne unterzogen und zeigten eine Überlegenheit gegenüber Placebo [14]. Monoklonale Antikörper haben ein Molekulargewicht von um die 150 kDa und können die intakte Blut-Hirn-Schranke nicht überwinden. Daher bezeichnet man diese als „large molecules“ im Gegensatz zu herkömmlichen Pharmaka und den „Gepanten“ [15], die „small molecules“ darstellen. Aufgrund des Herstellungsprozesses werden
- Tab. 1 Design der STRIVE-Studie [17]

\begin{tabular}{|l|l|}
\hline $\begin{array}{l}\text { Studienziel } \\
\text { Studiendesign }\end{array}$ & $\begin{array}{l}\text { Prophylaxe der episodischen Migräne } \\
\text { multizentrisch, doppelblind, randomisiert, } \\
\text { placebokontrolliert }\end{array}$ \\
\hline $\begin{array}{l}\text { Einschlusskriterium } \\
4-14 \text { Migränetage, }<65 \text { Jahre }\end{array}$ \\
\hline $\mathrm{n}$ Patienten & $\mathrm{n}=955$ \\
\hline Intervention & $\begin{array}{l}\text { Placebo }(\mathrm{n}=319), 70 \mathrm{mg} \text { Erenumab }(\mathrm{n}=317), \\
140 \mathrm{mg} \text { Erenumab }(\mathrm{n}=319)\end{array}$ \\
\hline $\begin{array}{l}\text { Behandlungsdauer } \\
\text { Primärer Endpunkt }\end{array}$ & $\begin{array}{l}\text { Reduktion der Migränetage/Monat in den } \\
\text { Monaten 4-6 }\end{array}$ \\
\hline $\begin{array}{l}\text { Wichtige Ausschluss- } \\
\text { kriterien }\end{array}$ & $>2$ gescheiterte Prophylaxen \\
\hline NCT-Nummer & NCT02456740 \\
\hline
\end{tabular}

vollhumane, rekombinante Antikörper (Endung „umab“) von humanisierten Antikörpern, die noch murine Anteile enthalten, unterschieden (Endung „zumab“). Vollhumane und humanisierte monoklonale Antikörper sind hochspezifisch und führen nur in minimalem Umfang zur Bildung von Autoantikörpern. Aufgrund ihrer biologischen Eigenschaften haben die Antikörper gegen den Liganden CGRP oder den CGRP-Rezeptor selbst ein günstiges Nebenwirkungsprofil. Dies hängt auch mit der Größe der Antikörper zusammen, da sie die Blut-Hirn-Schranke nicht in relevantem Ausmaß überwinden und keine zentralnervösen Nebenwirkungen haben. Bedingt durch den Abbau zu Aminosäuren, interagieren sie durch Umgehung hepatischer und renaler Eliminationsschritte nicht mit anderen Medikamenten. Monoklonale Antikörper müssen entweder subkutan oder intravenös verabreicht werden, wobei die entsprechenden Dosierungsintervalle abhängig von der Halbwertzeit und der Dosis zwischen 4 Wochen und für Fremanezumab 3 Monaten liegen.

Im Folgenden werden die Ergebnisse der Phase-3-Studien zur episodischen und chronischen Migräne dargestellt. Studien, welche die einzelnen Antikörper vergleichen, fehlen ebenso wie Vergleichsstudien mit den bisher etablierten und empfohlenen Migräneprophylaktika. Um einen indirekten Vergleich zu ermöglichen, wird über die Studien hinweg die $50 \%$-Responderrate benutzt. Es muss aber berücksichtigt werden, dass die Einschlusskriterien und Definitionen der Endpunkte in den referierten Studien zum Teil unterschiedlich waren und daher ein direkter Vergleich der Wirksamkeit der einzelnen Antikörper nicht möglich ist. Im zweiten Teil der Übersicht werden die Ergebnisse für wichtige Untergruppen von Patienten beschrieben.

\section{Erenumab zur Prophylaxe der episodischen Migräne}

Die Darstellung der Studienergebnisse für Erenumab stützt sich auf eine Übersichtsarbeit von Diener und Gaul [16].

\section{Die STRIVE-Studie}

Die erste Phase-3-Studie bei der episodischen Migräne war eine randomisierte placebokontrollierte Studie (STRIVE-Studie), in der die Migränepatienten über eine Zeitraum von 6 Monaten einmal 
pro Monat entweder Erenumab 70 mg, 140 mg oder Placebo subkutan injiziert bekamen [17]. Der primäre Endpunkt der Studie war die Änderung der Migränehäufigkeit zwischen der Baseline und den Monaten 4 bis 6, gemessen mit der mittleren Zahl der Migränetage pro Monat. Sekundäre Endpunkte waren die $50 \%$-Responderrate, die Zahl der Tage mit Einnahme von Akutmedikation und die Änderung der Lebensqualität, gemessen mit dem Migraine Physical Function Impact Diary (MPFID).

In die Studie wurden insgesamt 955 Patienten eingeschlossen. 319 erhielten Placebo, 317 die niedrige $(70 \mathrm{mg})$ und 319 die hohe Dosis (140 mg) von Erenumab. Das mittlere Alter der Patienten betrug 41 Jahre und $85 \%$ waren Frauen. 60 \% benutzten zur Behandlung der Migräneattacken Triptane und $78 \%$ Analgetika. $40 \%$ der Patienten hatten Erfahrung mit anderen Medikamenten zur Migräneprophylaxe. 40 \% gaben an, dass frühere Migräneprophylaxen entweder nicht wirksam waren oder inakzeptable Nebenwirkungen hatten. In der Baseline-Phase hatten die Patienten im Mittel 8,2 Migränetage pro Monat und 9,3 Kopfschmerztage. Sie nahmen im Mittel an 3,4 Tagen pro Monat Triptane ein.

Die Reduktion der Migränetage pro Monat betrug 3,2 in der 70-mg-Erenumab-Gruppe und 3,7 in der 140-mg-Erenumab-Gruppe, verglichen mit 1,8 Tagen in der Placebo-Gruppe ( $\triangleright$ Tab. 2). Dieser Unterschied war statistisch signifikant. Die $50 \%$-Responderrate, bezogen auf die monatlichen Migränetage, betrug 43,3\% für die niedrige Dosis und 50 \% für die hohe Dosis von Erenumab, verglichen mit 26,6\% in der Placebo-Gruppe. Auch dieser Unterschied war signifikant. Signifikante Unterschiede zeigten sich auch für die Einnahme spezifischer Migränemittel (z. B. Triptane), die um 1,1 Tage in der mit $70 \mathrm{mg}$ behandelten Gruppe und 1,6 Tage in der mit 140 mg behandelten Gruppe abnahm, verglichen mit 0,2 Tagen in der Placebo-Gruppe. Die Scores auf der MPFID-Skala (Migraine Physical Function Impact Diary), welche die körperliche Beeinträchtigung misst, verbesserten sich um 4,2 und 4,8 Punkte in den Erenumab-Gruppen, verglichen mit 2,4 Punkten in der Placebo-Gruppe. Auch dieser Unterschied war signifikant. Die Häufigkeit unerwünschter Arzneimittelwirkungen war zwischen Erenumab und Placebo nicht unterschiedlich.

\section{Die ARISE-Studie}

Die zweite Phase-3-Studie (ARISE) war eine randomisierte, doppelblinde, placebokontrollierte Studie, in die 577 Patienten mit episodischer Migräne eingeschlossen wurden [18]. Die Patienten erhielten entweder alle 4 Wochen 70 mg Erenumab subkutan oder Placebo. Der primäre Endpunkt war die Abnahme der Migränetage pro Monat. Sekundäre Endpunkte waren die 50 \%-Responderrate für Migränetage, die Veränderung der Tage, an denen eine migränespezifische symptomatische Akutmedikation eingenommen wurde (z. B. Triptane), und eine Verbesserung um 5 oder mehr Punkte des „Migraine Physical Function Impact Diary Score“. Diese Endpunkte wurden am Ende der dreimonatigen Behandlungsphase erfasst.

Die Patienten waren im Mittel 42 Jahre alt und $85 \%$ waren Frauen. Die Migräne bestand im Mittel seit 20 Jahren. Etwa die Hälfte der Patienten hatte eine Migräne mit Aura. Die Hälfte der Patienten hatte bisher keine Migräneprophylaxe erhalten. $60 \%$ der Patienten nahmen spezifische Migränemittel wie Triptane zur Behandlung akuter Migräneattacken ein. Die Zahl der Migränetage pro Monat betrug bei Studienbeginn im Mittel 8,2 Tage.
- Tab. 2. Erenumab in der Prophylaxe der episodischen Migräne, STRIVE [17]

\begin{tabular}{|c|c|c|c|}
\hline & $\begin{array}{l}\text { Placebo } \\
(n=319)\end{array}$ & $\begin{array}{l}\text { Erenumab } \\
70 \mathrm{mg} \\
(\mathrm{n}=317)\end{array}$ & $\begin{array}{l}\text { Erenumab } \\
140 \mathrm{mg} \\
(\mathrm{n}=319)\end{array}$ \\
\hline $\begin{array}{l}\text { Mean monthly migrai- } \\
\text { ne days (MMD) bei } \\
\text { Studienbeginn }\end{array}$ & 8,3 & 8,3 & 8,3 \\
\hline $\begin{array}{l}\text { Reduktion der Migrä- } \\
\text { netage (MMD) in den } \\
\text { Monaten 4-6 }\end{array}$ & $-1,6$ & $-3,2$ & $-3,7$ \\
\hline $\begin{array}{l}\text { Zahl der MMD in den } \\
\text { Monaten 4-6 (\% der } \\
\text { Baseline) }\end{array}$ & $\begin{array}{l}6,5 \\
(78 \%)\end{array}$ & $\begin{array}{l}5,1 \\
(61 \%)\end{array}$ & $\begin{array}{l}4,6 \\
(55 \%)\end{array}$ \\
\hline $\begin{array}{l}>50 \% \text {-Responderra- } \\
\text { te für MMD in den } \\
\text { Monaten } 4-6\end{array}$ & $84(26,6 \%)$ & $\begin{array}{l}138(43,3 \%) \\
\text { TG }=17 \% \\
(95 \%-C l= \\
9-24 \%) \\
\text { NNT }=5,9\end{array}$ & $\begin{array}{l}159(50,0 \%) \\
\text { TG }=23 \% \\
(95 \% \mathrm{Cl}= \\
16-31 \%) \\
\text { NNT }=4,3\end{array}$ \\
\hline SAE & 7 & 8 & 6 \\
\hline $\begin{array}{l}\text { AE mit Studienab- } \\
\text { bruch }\end{array}$ & 8 & 7 & 7 \\
\hline \multicolumn{4}{|c|}{$\begin{array}{l}\text { TG= Therapeutischer Gewinn (Differenz zwischen Verum und } \\
\text { Placebo), NNT = Number needed to treat, } \mathrm{SAE}=\text { schwerwiegende } \\
\text { unerwünschte Arzneimittelwirkungen, } \mathrm{AE}=\text { unerwünschte Arznei- } \\
\text { mittelwirkungen }\end{array}$} \\
\hline
\end{tabular}

- Tab. 3 Design der ARISE-Studie [18]

\begin{tabular}{|c|c|}
\hline Studienziel & Prophylaxe der episodischen Migräne \\
\hline Studiendesign & $\begin{array}{l}\text { multizentrisch, doppelblind, randomisiert, place- } \\
\text { bokontrolliert }\end{array}$ \\
\hline $\begin{array}{l}\text { Einschlusskrite- } \\
\text { rium }\end{array}$ & $\geq 4-<15$ Migränetage, 18-65 Jahre \\
\hline n Patienten & $\mathrm{n}=577$ \\
\hline Intervention & Placebo $(n=291), 70 \mathrm{mg}$ Erenumab $(n=286)$ \\
\hline $\begin{array}{l}\text { Behandlungs- } \\
\text { dauer }\end{array}$ & 12 Wochen \\
\hline $\begin{array}{l}\text { Primärer End- } \\
\text { punkt }\end{array}$ & Änderung der Migränetage/Monat \\
\hline $\begin{array}{l}\text { Sekundäre End- } \\
\text { punkte }\end{array}$ & $\begin{array}{l}\geq 50 \% \text { Reduktion der Migränetage/Monat } \\
\text { Änderung der Einnahme von Medikamenten zur } \\
\text { Therapie der Migräneattacke } \\
\geq 5 \text { Punkte Reduktion des Migraine Physical Functi- } \\
\text { on Impact Diary }\end{array}$ \\
\hline $\begin{array}{l}\text { Wichtige Aus- } \\
\text { schlusskriterien }\end{array}$ & $>2$ gescheiterte Prophylaxen in der Vergangenheit \\
\hline NCT-Nummer & NCT02483585 \\
\hline
\end{tabular}

Unter Erenumab kam es innerhalb von 3 Monaten zu einer signifikanten Abnahme von 2,9 Migränetagen pro Monat, verglichen mit 1,8 Tagen unter Placebo ( $\triangleright$ Tab. 4). Die $50 \%$-Responderrate betrug 39,7 \% für Erenumab und 29,5\% für Placebo mit einer Odds Ratio (OR) von 1,9, einem 95\%-Konfidenzintervall zwischen 1,12 
- Tab. 4 Ergebnisse der ARISE-Studie mit Erenumab bei Patienten mit episodischer Migräne

\begin{tabular}{|c|c|c|}
\hline & $\begin{array}{l}\text { Placebo } \\
(\mathrm{n}=\mathbf{2 8 8})\end{array}$ & $\begin{array}{l}\text { Erenumab } 70 \mathrm{mg} \\
(\mathrm{n}=282)\end{array}$ \\
\hline $\begin{array}{l}\text { Mean monthly migraine days } \\
\text { (MMD) bei Studienbeginn }\end{array}$ & 8,4 & 8,1 \\
\hline $\begin{array}{l}\text { Reduktion der MMD von der Base- } \\
\text { line zu Monat } 3\end{array}$ & $-1,8$ & $-2,9$ \\
\hline $\begin{array}{l}\text { Zahl der MMD im Monat } 3 \\
\text { (\% der Baseline) }\end{array}$ & $6,6(79 \%)$ & $5,2(64 \%)$ \\
\hline $\begin{array}{l}>50 \% \text {-Responderrate für MMD im } \\
\text { Monat } 3\end{array}$ & $85(29,5 \%)$ & $\begin{array}{l}112(39,7 \%) \\
\text { TG }=10 \% \\
(95 \%-C l=2-18 \%) \\
\text { NNT }=10\end{array}$ \\
\hline SAE & 5 & 3 \\
\hline AE mit Studienabbruch & 1 & 5 \\
\hline \multicolumn{3}{|c|}{$\begin{array}{l}\text { TG= Therapeutischer Gewinn (Differenz zwischen Verum und } \\
\text { Placebo), NNT = Number needed to treat, SAE = schwerwiegende } \\
\text { unerwünschte Arzneimittelwirkung, } A E=\text { unerwünschte Arzneimit- } \\
\text { telwirkung }\end{array}$} \\
\hline
\end{tabular}

- Tab. 5 Design der LIBERTY-Studie [20]

\begin{tabular}{|c|c|}
\hline Studienziel & Prophylaxe der episodischen Migräne \\
\hline Studiendesign & $\begin{array}{l}\text { multizentrisch, doppelblind, randomisiert, placebo- } \\
\text { kontrolliert }\end{array}$ \\
\hline $\begin{array}{l}\text { Einschlusskrite- } \\
\text { rium }\end{array}$ & $\begin{array}{l}\geq 4-<15 \text { Migränetage, } 18-65 \text { Jahre, in der Vergan- } \\
\text { genheit waren } 2-4 \text { prophylaktische Therapien nicht } \\
\text { wirksam }\end{array}$ \\
\hline n Patienten & $\mathrm{n}=246$ \\
\hline Intervention & Placebo $(n=120), 140 \mathrm{mg}$ Erenumab $(n=121)$ \\
\hline $\begin{array}{l}\text { Behandlungs- } \\
\text { dauer }\end{array}$ & 12 Wochen \\
\hline $\begin{array}{l}\text { Primärer End- } \\
\text { punkt }\end{array}$ & $\geq 50 \%$-Reduktion der Migränetage/Monat \\
\hline $\begin{array}{l}\text { Sekundäre End- } \\
\text { punkte }\end{array}$ & $\begin{array}{l}\text { Reduktion der Migränetage/Monat, Verände- } \\
\text { rung der monatlichen Tage mit Akutmedikation, } \\
75 \% \text { - und } 100 \% \text {-Responderraten für Migränetage, } \\
\text { Änderungen im Migraine Physical Function Impact } \\
\text { Diary und Work Productivity and Activty Impair- } \\
\text { ment Score }\end{array}$ \\
\hline NCT-Nummer & NCT03096834 \\
\hline
\end{tabular}

und 2,27. Es zeigte sich auch eine signifikante Reduktion der Tage, an denen spezifische Migränemedikamente eingenommen wurden, wobei die Reduktion 1,2 Tage unter Erenumab und 0,6 Tage unter Placebo betrug. Dieser Unterschied war mit einem p-Wert von 0,002 signifikant. Die Leistungsfähigkeit, gemessen mit „Physical Impairment and Impact on Everyday Activities Domain Score measured by the Migraine Physical Function Impact Diary “ war nicht unterschiedlich. Erenumab hatte ein Nebenwirkungsprofil vergleichbar mit Placebo. Gelegentlich kam es zu Infektionen der
- Tab. 6 Ergebnisse der LIBERTY-Studie mit Erenumab bei Patienten mit episodischer Migräne [20]

\begin{tabular}{|c|c|c|}
\hline & $\begin{array}{l}\text { Placebo } \\
(n=125)\end{array}$ & $\begin{array}{l}\text { Erenumab } 140 \mathrm{mg} \\
(\mathrm{n}=121)\end{array}$ \\
\hline $\begin{array}{l}\text { Mean monthly migraine days } \\
\text { (MMD) bei Studienbeginn }\end{array}$ & 9,2 & 9,3 \\
\hline $\begin{array}{l}\text { Reduktion der MMD von der Base- } \\
\text { line zu Monat } 3\end{array}$ & $-0,2$ & $-1,8$ \\
\hline $\begin{array}{l}\text { Zahl der MMD im Monat } 3 \\
\text { (\% der Baseline) }\end{array}$ & 9,0 (97\%) & $7,5(80 \%)$ \\
\hline $\begin{array}{l}>50 \% \text {-Responderrate für MMD im } \\
\text { Monat } 3\end{array}$ & 17 (14\%) & $\begin{array}{l}36(30 \%) \\
\text { TG }=16 \% \\
(95 \%-C l=5-26 \%) \\
\text { NNT }=6,3\end{array}$ \\
\hline SAE & 1 & 2 \\
\hline AE mit Studienabbruch & 1 & 0 \\
\hline \multicolumn{3}{|c|}{$\begin{array}{l}\text { TG = Therapeutischer Gewinn (Differenz zwischen Verum und } \\
\text { Placebo), NNT = Number needed to treat, SAE = schwerwiegende } \\
\text { unerwünschte Arzneimittelwirkungen, } \mathrm{AE}=\text { unerwünschte Arznei- } \\
\text { mittelwirkungen }\end{array}$} \\
\hline
\end{tabular}

oberen Atemwege und einige Patienten beklagten Schmerzen an der Injektionsstelle (12/289 mit Placebo, 17/283 mit Erenumab). Nur 5 Patienten brachen in der Erenumab-Gruppe die Behandlung wegen Nebenwirkungen ab.

\section{Die LIBERTY-Studie}

Die LIBERTY-Studie untersuchte prospektiv die Gabe von Erenumab 140 mg alle 4 Wochen bei Patienten, bei denen in der Vergangenheit zwischen 2 und 4 Substanzen zur Migräneprophylaxe nicht wirksam waren oder nicht vertragen wurden [19]. In die Studie wurden 246 Patienten aufgenommen und über 12 Wochen mit Erenumab oder Placebo behandelt. Anschließend wurden die Patienten über 156 Wochen offen weiterbehandelt. Der primäre Endpunkt war eine mindestens $50 \%$ ige Reduktion der Migränetage in den Wochen 9-12 ( Tab.5).

Im Rahmen der Studie hatten 39\% der Patienten 2 vergebliche Therapieversuche mit Migräneprophylaktika, $38 \% 3$ Versuche und $23 \% 4$ Versuche. Die am häufigsten abgebrochenen Therapien waren Topiramat (85\%), Amitriptylin (45\%), Propranolol (45\%) und Metoprolol (38\%). In der Woche 12 betrug die $50 \%$-Responderrate unter Erenumab 30,3\% und in der Placebo-Gruppe 13,7\%. Dies entspricht einer Odds Ratio von 2,73 mit einem $95 \%$-Cl von 1,435,19 . Erenumab war auch für alle sekundären Endpunkte wirksamer als Placebo. Zusätzlich wurden patientenorientierte Endpunkte untersucht. Hier zeigte sich eine Überlegenheit von Erenumab in der HIT-6-Skala (Headache Impact Test) und einem Score, der die Produktivität am Arbeitsplatz misst (WPAI = Work Productivity and Activity Impairment Score).

Fasst man die randomisierten Studien zur Wirksamkeit von Erenumab bei der episodischen Migräne zusammen, sind beide Dosen von 70 und $140 \mathrm{mg}$ besser wirksam als Placebo. Die Reduktion der Migränetage pro Monat lag zwischen 2,9 und 3,7 Tagen, verglichen mit 1,8 bis 2,3 Tagen für Placebo. Über die 3 Studien hinweg 
- Tab.7 Fremanezumab zur Prophylaxe der episodischen Migräne (HALO) [21]

\begin{tabular}{l|l} 
Studienziel & Prophylaxe der episodischen Migräne \\
\hline Studiendesign & $\begin{array}{l}\text { multizentrisch, doppelblind, randomisiert, placebo- } \\
\text { kontrolliert }\end{array}$ \\
\hline $\begin{array}{l}\text { Einschlusskrite- } \\
\text { rium }\end{array}$ & $\geq 4$ Migränetage/Monat \\
\hline $\begin{array}{l}\mathrm{n} \text { Patienten } \\
\text { Intervention }\end{array}$ & $\begin{array}{l}\mathrm{n}=875 \\
\text { Placebo, } 225 \mathrm{mg} \text { Fremanezumab s. c. pro Monat, }\end{array}$ \\
\hline $\begin{array}{l}\text { Behandlungs- } \\
\text { dauer }\end{array}$ & 12 Wochen \\
\hline $\begin{array}{l}\text { Primärer End- } \\
\text { punkt }\end{array}$ & Reduktion der Migränetage/Monat über 12 Wochen \\
\hline $\begin{array}{l}\text { Sekundäre End- } \\
\text { punkte }\end{array}$ & $\begin{array}{l}\text { Tage mit Einnahme von Akutmedikation, Migraine } \\
\text { Disabiity Assessment Score (MIDAS) }\end{array}$ \\
\hline $\begin{array}{l}\text { Wichtige Aus- } \\
\text { schlusskriterien }\end{array}$ & $>2$ gescheiterte Prophylaxen in der Vergangenheit \\
\hline \begin{tabular}{l} 
NCT-Nummer \\
\hline
\end{tabular} & NTC02629861 \\
\hline
\end{tabular}

betrug die mittlere Zahl der Migränetage in der Baseline 8,4 und wurde durch Erenumab im Mittel um 3,3 Tage reduziert. Die mittlere $50 \%$-Responderrate lag bei $45 \%$ für Erenumab und $24-27 \%$ für Placebo.

\section{Fremanezumab zur Prophylaxe der episodischen Migräne}

Fremanezumab wurde in einer ersten Phase-3-Studie mit Placebo verglichen [21]. Es handelte sich um eine doppelblinde, placebokontrollierte Parallelgruppenstudie, die an 123 Kopfschmerzzentren in 9 Ländern durchgeführt wurde. Nach einer 28-tägigen Baseline erfolgte die Behandlung über 12 Wochen mit einer subkutanen Gabe von Fremanezumab. Einschlusskriterien waren unter anderem ein Alter zwischen 18 und 70 Jahren und eine episodische Migräne mit 4-14 Kopfschmerztagen pro Monat. Es wurden nur Patienten eingeschlossen, die in der Vergangenheit auf maximal 2 Klassen einer migränepräventiven Therapie entweder nicht angesprochen hatten, diese nicht vertragen hatten oder bei denen die entsprechende Medikamentenklasse kontraindiziert war. Etwa $20 \%$ der Studienteilnehmer waren stabil auf eine medikamentöse Migräneprophylaxe eingestellt und führten diese in der Studie fort. Die Patienten wurden in 3 Gruppen randomisiert. 290 Patienten erhielten $225 \mathrm{mg}$ Fremanezumab alle 4 Wochen, 291 Patienten erhielten eine einmalige Dosis von 675 mg Fremanezumab und 294 Patienten erhielten Placebo. Der primäre Endpunkt war die mittlere Änderung der Migränetage pro Monat über die 12-wöchige Behandlungsphase.

Die Patienten waren im Mittel 42 Jahre alt und $85 \%$ waren Frauen. Die Migräne bestand im Mittel seit 20 Jahren. In der Baseline hatten die Patienten im Mittel 9 Migränetage und an 7,7 Tagen nahmen die Patienten Medikamente zur Behandlung der Migräneattacke ein. An 6-7 Tagen erfolgte die Einnahme einer spezifischen Migränemedikation. In der Therapiegruppe, die einmal monatlich Fremanezumab erhielt, kam es zu einer signifikanten Abnah-
- Tab. 8 Fremanezumab zur Prophylaxe der episodischen Migräne [21]

\begin{tabular}{|c|c|c|c|}
\hline & $\begin{array}{l}\text { Placebo } \\
n=294\end{array}$ & $\begin{array}{l}\text { Fremanezumab } \\
1 \times \text { pro Monat } \\
n=290\end{array}$ & $\begin{array}{l}\text { Fremanezumab } \\
1 \times \text { für } 3 \text { Monate } \\
n=291\end{array}$ \\
\hline $\begin{array}{l}\text { Mean monthly } \\
\text { migraine days } \\
\text { (MMD) bei Studi- } \\
\text { enbeginn }\end{array}$ & 9,1 & 8,9 & 9,2 \\
\hline $\begin{array}{l}\text { Reduktion der } \\
\text { MMD von der Ba- } \\
\text { seline zu Monat } 3\end{array}$ & $-2,6$ & $-4,0$ & $-3,9$ \\
\hline $\begin{array}{l}\text { Zahl der MMD im } \\
\text { Monat } 3 \\
\text { (\% der Baseline) }\end{array}$ & $\begin{array}{l}6,5 \\
71,4 \%\end{array}$ & $\begin{array}{l}4,9 \\
55,1 \%\end{array}$ & $\begin{array}{l}5,3 \\
57,6 \%\end{array}$ \\
\hline $\begin{array}{l}>50 \% \text {-Responder- } \\
\text { rate für MMD im } \\
\text { Monat } 3\end{array}$ & $\begin{array}{l}82 \\
(27,9 \%)\end{array}$ & $\begin{array}{l}138(47,7 \%) \\
\text { TG }=20 \% \\
(95 \%-C l= \\
12-28 \%) \\
\text { NNT }=5,1\end{array}$ & $\begin{array}{l}129(44,4 \%) \\
\mathrm{TG}=16 \% \\
(95 \%-\mathrm{Cl}= \\
9-24 \%) \\
\text { NNT }=6,1\end{array}$ \\
\hline SAE & 7 & 3 & 3 \\
\hline $\begin{array}{l}\text { AE mit Studienab- } \\
\text { bruch }\end{array}$ & 5 & 5 & 5 \\
\hline \multicolumn{4}{|c|}{$\begin{array}{l}\text { TG = Therapeutischer Gewinn (Differenz zwischen Verum und } \\
\text { Placebo), NNT = Number needed to treat, SAE = schwerwiegende } \\
\text { unerwünschte Arzneimittelwirkungen, AE = unerwünschte Arznei- } \\
\text { mittelwirkungen }\end{array}$} \\
\hline
\end{tabular}

me von 4,0 Migränetagen, verglichen mit 2,6 Migränetagen unter Placebo. Bei der einmaligen höheren Dosis von Fremanezumab kam es zu einer Abnahme der Migränetage pro Monat von 3,9 Tagen. Auch hier war der Unterschied zu Placebo (Abnahme um 2,6 Tage) signifikant. Die $50 \%$-Responderrate, bezogen auf die Migränetage pro Monat, betrug $47,7 \%$ in der Fremanezumab-Gruppe, in der 3-mal injiziert wurde, $44,4 \%$ bei den Patienten, die nur 1-mal mit $675 \mathrm{mg}$ Fremanezumab behandelt wurden, und $27,9 \%$ in der Placebo-Gruppe. Diese Unterschiede waren signifikant $(\triangleright$ Tab. 8$)$. Signifikante Unterschiede zugunsten von Fremanezumab ergaben sich auch für alle sekundären Endpunkte wie beispielsweise die Einnahmetage von Medikamenten zur Behandlung von Kopfschmerzen sowie die Beeinträchtigung durch die Migräne, gemessen mit dem MIDAS-Score. Bezüglich unerwünschter Arzneimittelwirkungen ergaben sich keine signifikanten Unterschiede zwischen den 3 Therapiegruppen. Am häufigsten wurden Schmerzen an der Injektionsstelle und Infektionen der oberen Atemwege beklagt. Die Therapie wurde von jeweils 5 Patienten in jeder Therapiegruppe wegen Nebenwirkungen abgebrochen.

Bei Patienten mit episodischer Migräne, die auf mindestens 2 Klassen von Migräneprophylaktika in der Vergangenheit nicht ansprachen, führte Fremanezumab über eine 12-wöchige Behandlungsperiode, verglichen mit Placebo, zu einer statistisch signifikanten Reduktion von 1,3 bis 1,5 Migränetagen pro Monat. Die Behandlung mit Fremanezumab wurde gut toleriert. 
\Tab.9 Galcanezumab zur Prophylaxe der episodischen Migräne

\begin{tabular}{|c|c|c|}
\hline & EVOLVE-1 [22] & EVOLVE-2 [23] \\
\hline Studienziel & $\begin{array}{l}\text { Prophylaxe der episodi- } \\
\text { schen Migräne }\end{array}$ & $\begin{array}{l}\text { Prophylaxe der episodi- } \\
\text { schen Migräne }\end{array}$ \\
\hline Studiendesign & $\begin{array}{l}\text { doppelblind, randomi- } \\
\text { siert, placebokontrolliert }\end{array}$ & $\begin{array}{l}\text { doppelblind, randomi- } \\
\text { siert, placebokontrolliert }\end{array}$ \\
\hline $\begin{array}{l}\text { Einschlusskri- } \\
\text { terium }\end{array}$ & $\begin{array}{l}\text { 4-14 Migränetage/Mo- } \\
\text { nat, 18-65 Jahre }\end{array}$ & $\begin{array}{l}\text { 4-14 Migränetage/Mo- } \\
\text { nat, 18-65 Jahre }\end{array}$ \\
\hline n Patienten & $\mathrm{n}=858$ & $n=915$ \\
\hline Intervention & $\begin{array}{l}\text { Placebo, } 120 \text { mg Galcane- } \\
\text { zumab, } 240 \text { mg Galcane- } \\
\text { zumab pro Monat s. c. }\end{array}$ & $\begin{array}{l}\text { Placebo, } 120 \text { mg Galcane- } \\
\text { zumab, } 240 \text { mg Galcane- } \\
\text { zumab pro Monat s.c. }\end{array}$ \\
\hline $\begin{array}{l}\text { Behandlungs- } \\
\text { dauer }\end{array}$ & 6 Monate & 6 Monate \\
\hline $\begin{array}{l}\text { Primärer } \\
\text { Endpunkt }\end{array}$ & $\begin{array}{l}\text { Reduktion der Migräneta- } \\
\text { ge Monat 1-6 }\end{array}$ & $\begin{array}{l}\text { Reduktion der Migräneta- } \\
\text { ge Monat 1-6 }\end{array}$ \\
\hline $\begin{array}{l}\text { Sekundäre } \\
\text { Endpunkte }\end{array}$ & $\begin{array}{l}50 \%-, 75 \%-, 100 \% \text {-Re- } \\
\text { sponderrate, Tage mit } \\
\text { Akutmedikation, } \\
\text { MIDAS, MSQ }\end{array}$ & $\begin{array}{l}50 \%-, 75 \%-, 100 \%-\text {-Re- } \\
\text { sponderrate, Tage mit } \\
\text { Akutmedikation, MIDAS, } \\
\text { MSQ }\end{array}$ \\
\hline $\begin{array}{l}\text { Wichtige } \\
\text { Ausschlusskri- } \\
\text { terien }\end{array}$ & $\begin{array}{l}\geq 3 \text { erfolglose vorherige } \\
\text { Prophylaxen, keine ande- } \\
\text { re Prophylaxe }\end{array}$ & $\begin{array}{l}\geq 3 \text { erfolglose vorherige } \\
\text { Prophylaxen, keine ande- } \\
\text { re Prophylaxe }\end{array}$ \\
\hline NCT-Nummer & NCT02614183 & NCT02614196 \\
\hline
\end{tabular}

MIDAS = Migraine Disability Assessment Score , MSQ = Migraine Specific Quality of Life Questionnaire

- Tab.10 Galcanezumab zur Prophylaxe der episodischen Migräne. EVOLVE-1 [22]

\begin{tabular}{|c|c|c|c|}
\hline EVOLVE-1 & $\begin{array}{l}\text { Placebo } \\
(n=433)\end{array}$ & $\begin{array}{l}\text { Galcanezumab } \\
120 \mathrm{mg} \\
(\mathrm{n}=213)\end{array}$ & $\begin{array}{l}\text { Galcanezumab } \\
240 \mathrm{mg} \\
(\mathrm{n}=212)\end{array}$ \\
\hline $\begin{array}{l}\text { Mean monthly } \\
\text { migraine days } \\
\text { (MMD) bei Stu- } \\
\text { dienbeginn }\end{array}$ & 9,1 & 9,2 & 9,1 \\
\hline $\begin{array}{l}\text { Reduktion der } \\
\text { MMD über die } \\
\text { Monate } 1-3\end{array}$ & $-2,8$ & $-4,7$ & $-4,6$ \\
\hline $\begin{array}{l}\text { Zahl der MMD } \\
\text { im Monat } 6 \text { (\% } \\
\text { der Baseline) }\end{array}$ & $6,3(69 \%)$ & $4,5(49 \%)$ & $4,5(49 \%)$ \\
\hline $\begin{array}{l}>50 \% \text {-Res- } \\
\text { ponderrate für } \\
\text { MMD über die } \\
\text { Monate } 1-3\end{array}$ & $39 \%$ & $\begin{array}{l}62 \% \\
\text { TG = 24\% } \\
(95 \%-\mathrm{Cl}=15- \\
32 \%)\end{array}$ & $\begin{array}{l}61 \% \\
\text { TG }=22 \% \\
(95 \%-C l=14- \\
30 \%)\end{array}$ \\
\hline NNT & & 4,3 & 4,5 \\
\hline
\end{tabular}

TG = Therapeutischer Gewinn (Differenz zwischen Verum und Placebo) , NNT = Number needed to treat
- Tab.11 Galcanezumab zur Prophylaxe der episodischen Migräne EVOLVE-2 [23]

\begin{tabular}{|c|c|c|c|}
\hline & $\begin{array}{l}\text { Placebo } \\
(n=461)\end{array}$ & $\begin{array}{l}\text { Galcanezumab } \\
120 \mathrm{mg} \\
(\mathrm{n}=231)\end{array}$ & $\begin{array}{l}\text { Galcanezumab } \\
240 \mathrm{mg} \\
(\mathrm{n}=223)\end{array}$ \\
\hline $\begin{array}{l}\text { Mean monthly } \\
\text { migraine days } \\
\text { (MMD) bei Studien- } \\
\text { beginn }\end{array}$ & 9,2 & 9,1 & 9,1 \\
\hline $\begin{array}{l}\text { Reduktion der MMD } \\
\text { über die Monate } \\
1-6\end{array}$ & $-2,3$ & $-4,3$ & $-4,2$ \\
\hline $\begin{array}{l}\text { Zahl der MMDs im } \\
\text { Monat } 6 \\
\text { (\% der Baseline) }\end{array}$ & 6,9 (75\%) & $4,8(53 \%)$ & 4,9 (54\%) \\
\hline $\begin{array}{l}>50 \% \text {-Responderra- } \\
\text { te für MMD über die } \\
\text { Monate } 1-6\end{array}$ & $36 \%$ & $\begin{array}{l}59 \% \\
\mathrm{TG}=23 \% \\
(95 \%-\mathrm{Cl}=15- \\
31 \%)\end{array}$ & $\begin{array}{l}57 \% \\
\text { TG }=20 \% \\
(95 \%-C l=13- \\
28 \%)\end{array}$ \\
\hline NNT & & 4,3 & 4,8 \\
\hline
\end{tabular}

TG = Therapeutischer Gewinn (Differenz zwischen Verum und Placebo), NNT = Number needed to treat

\section{Galcanezumab zur Prophylaxe der episodischen Migräne}

Die beiden EVOLVE-Studien (Evaluation of LY2951742 in the prevention of episodic migraine) waren doppelblinde, randomisierte, placebokontrollierte Studien, die die subkutanen Injektionen von Galcanezumab mit Placebo verglichen [22, 23]. Die Patienten erhielten über einen Zeitraum von 6 Monaten $1 \times$ monatlich eine subkutane Injektion von Galcanezumab 120 mg, 240 mg oder Placebo. Eingeschlossen wurden Patienten mit 4-14 Migränetagen/Monat. Der primäre Endpunkt der Studien war die mittlere Reduktion der Migränetage während der Studiendauer, verglichen mit der Baseline. Außerdem wurden die 50\%-, 75\%- und 100\%-Responderraten berechnet, Migränetage mit der Einnahme von Akutmedikation sowie die Lebensqualität und die Einschränkung im Alltag durch die Migräne. Eine vorbestehende medikamentöse Migräneprophylaxe musste vor Studieneinschluss beendet werden.

\section{Ergebnisse}

In die EVOLVE-1-Studie wurden 858 Patienten aufgenommen. Das mittlere Alter der Patienten betrug 40,7 Jahre und 84\% waren Frauen. In der Baseline-Periode betrug die mittlere Häufigkeit der Migränetage pro Monat 9,1. Beide Dosierungen von Galcanezumab waren signifikant besser wirksam als Placebo. Die Reduktion der Migränetage betrug im Mittel 4,7 Tage (120 mg) und 4,6 Tage (240 mg) für Galcanezumab, verglichen mit Placebo mit 2,8 Tagen $(p<0,001)$. Die Studie zeigte auch signifikante Unterschiede für alle sekundären Endpunkte zugunsten von Galcanezumab.

In die EVOLVE-2-Studie wurden 915 Patienten aufgenommen und ebenfalls mit $120 \mathrm{mg}(\mathrm{n}=231)$ oder $240 \mathrm{mg}(\mathrm{n}=223)$ Galcanezumab $1 \times$ monatlich behandelt. 461 Patienten erhielten Placebo. Die Patienten waren im Mittel 41,9 Jahre alt und 85,4\% waren 
weiblich. In der Baseline betrug die mittlere Häufigkeit der Migränetage 9,1 pro Monat. Die Reduktion der Migränetage betrug im Mittel 4,3 Tage (120 mg) und 4,2 Tage (240 mg) für Galcanezumab, verglichen mit Placebo mit 2,3 Tagen $(p<0,01)$. Auch in dieser Studie zeigte sich eine Überlegenheit von Galcanezumab gegenüber Placebo für die sekundären Zielparameter. Die $50 \%$-Responderraten betrugen in den beiden Studien 62,3\% und 59,3\% für die 120-mg-Dosis von Galcanezumab, 60,9\% und 56,5\% für die 240 -mg-Dosis, verglichen mit 38,6\% und $36 \%$ mit Placebo. Die $100 \%$-Responderraten betrugen 15,6\% und 11,5\% (120 mg), $14,6 \%$ und $13,8 \%$ (240 mg), verglichen mit Placebo 6,2\% und 5,7\%. Hierbei muss allerdings berücksichtigt werden, dass sich diese Raten nicht auf eine komplette Schmerzfreiheit über die gesamten 6 Monate bezogen, sondern auf mindestens einen (oder mehrere) attackenfreie Monate. Diese Raten lagen gepoolt für beide Studien bei 0,7 \% für $120 \mathrm{mg}$ und $1,4 \%$ für $240 \mathrm{mg}$ Galcanezumab [24].

Die Therapie mit Galcanezumab wurde sehr gut vertragen. Außer Reaktionen an der Injektionsstelle zeigten sich keine Unterschiede in den unerwünschten Arzneimittelwirkungen zwischen Verum und Placebo. Nur wenige Patienten brachen die Studie wegen Nebenwirkungen ab. Die Häufigkeiten waren 1,7\% und 2,3 \% für Placebo, 2,2 \% und 4,2\% für die 120-mg-Dosis und 4,0\% und 3,3\% für 240-mg-Dosis von Galcanezumab.

Der monoklonale Antikörper gegen CGRP Galcanezumab war in 2 randomisierten, doppelblinden, placebokontrollierten Studien über einen Zeitraum von 6 Monaten in der Prophylaxe der episodischen Migräne besser wirksam als Placebo. Zwischen den beiden Dosierungen von 120 und 240 mg bestanden keine Unterschiede in der Wirksamkeit.

\section{Eptinezumab zur Prophylaxe der episodischen Migräne}

Die hier vorgestellten Daten zu Eptinezumab zur episodischen Migräne müssen noch mit Zurückhaltung bewertet werden. Die Ergebnisse wurden auf Kongressen als Abstract und als Pressemeldung kommuniziert, aber noch nicht in einer Peer-reviewten Zeitschrift publiziert (Zeitpunkt August 2019).

In der PROMISE-1-Studie erhielten erwachsene Migränepatienten mit Kopfschmerzen an $\leq 14$ Tagen im Monat, von denen $\geq 4$ die ICHD-II-Kriterien für Migräne erfüllten, alle 12 Wochen Eptinezumab 30, 100, 300 mg intravenös oder Placebo. Der primäre Endpunkt war die Reduktion der monatlichen Migränetage über die Wochen 1-12. Die Studie erstreckte sich über insgesamt 48 Wochen. Für die Auswertung standen 888 Patienten zur Verfügung. Die durchschnittliche Zahl der Migränetage pro Monat in der Baseline betrug im Mittel 8,5 Tage in allen Behandlungsgruppen. Eptinezumab 30, 100 und $300 \mathrm{mg}$ vs. Placebo verringerte die Migränetage pro Monat gegenüber dem Ausgangswert in den Wochen 1-12 um -4,0, um -3,9, um $-4,3$ versus $-3,2$ für Placebo. Der Prozentsatz der Patienten mit einer $\geq 50 \%$ igen Reduktion der Migränetage pro Monat betrug für Eptinezumab 30 mg 50,2\%, für 100 mg 49,8\%, für 300 mg 56,3\% und für Placebo 37,4\%. Alle Unterschiede zwischen Eptinezumab und Placebo waren signifikant. Unerwünschte Arzneimittelwirkungen waren zwischen Eptinezumab und Placebo nicht unterschiedlich. Nur obere bronchopulmonale Infekte, Nasopharyngitis und Sinusitis waren numerisch unter Eptinezumab häufiger als unter Placebo.
- Tab.12 Eptinezumab zur Prophylaxe der episodischen Migräne

\section{PROMISE-1}

\begin{tabular}{|c|c|}
\hline & PROMISE-1 \\
\hline Studienziel & $\begin{array}{l}\text { Prophylaxe der episodischen Migräne mit hoher } \\
\text { Frequenz }\end{array}$ \\
\hline Studiendesign & randomisiert, doppelblind, placebokontrolliert \\
\hline $\begin{array}{l}\text { Einschlusskrite- } \\
\text { rium }\end{array}$ & $\begin{array}{l}\leq 14 \text { Kopfschmerztage/Monat davon } \geq 4 \text { Tage } \\
\text { Migräne }\end{array}$ \\
\hline n Patienten & $\mathrm{n}=888$ \\
\hline Intervention & $\begin{array}{l}\text { Eptinezumab } 30,100,300 \mathrm{mg} 1 \times \text { intravenös, } \\
\text { Placebo }\end{array}$ \\
\hline $\begin{array}{l}\text { Behandlungs- } \\
\text { dauer }\end{array}$ & Phase 1: 12 Wochen, Phase 2: 48 Wochen \\
\hline $\begin{array}{l}\text { Primärer End- } \\
\text { punkt }\end{array}$ & $\begin{array}{l}\text { Reduzierung der monatlichen Migränetage in } \\
\text { den Monaten } 1 \text { bis } 3\end{array}$ \\
\hline $\begin{array}{l}\text { Sekundäre End- } \\
\text { punkte }\end{array}$ & $\begin{array}{l}50 \% \text { - und } 75 \% \text {-Responderraten für Migränetage/ } \\
\text { Monat, SF-36 }\end{array}$ \\
\hline NCT-Nummer & NCT0255989 \\
\hline
\end{tabular}

Tab.13 Eptinezumab zur Prophylaxe der episodischen Migräne PROMISE-1, zitiert in Tepper 2018 [25]

\begin{tabular}{|c|c|c|c|c|}
\hline & $\begin{array}{l}\text { Placebo } \\
n=222\end{array}$ & $\begin{array}{l}\text { Eptinezu- } \\
\text { mab } \\
30 \mathrm{mg} \\
\mathrm{n}=\mathbf{2 1 9}\end{array}$ & $\begin{array}{l}\text { Eptine- } \\
\text { zumab } \\
100 \mathrm{mg} \\
\mathrm{n}=223\end{array}$ & $\begin{array}{l}\text { Eptine- } \\
\text { zumab } \\
300 \mathrm{mg} \\
\mathrm{n}=224\end{array}$ \\
\hline $\begin{array}{l}\text { Mean monthly } \\
\text { migraine days } \\
\text { (MMD) bei Stu- } \\
\text { dienbeginn }\end{array}$ & 8,4 & 8,7 & 8,7 & 8,6 \\
\hline $\begin{array}{l}\text { Reduktion der } \\
\text { MMD von der } \\
\text { Baseline zu } \\
\text { Monat } 3\end{array}$ & $-3,2$ & $-4,0$ & $-3,9$ & $-4,3$ \\
\hline $\begin{array}{l}\text { Zahl der MMD } \\
\text { im Monat } 3 \\
\text { (\% der Base- } \\
\text { line) }\end{array}$ & $5,2(62 \%)$ & 4,7 (54\%) & 4,8 (55\%) & $4,3(50 \%)$ \\
\hline $\begin{array}{l}\text { Zahl der MMD } \\
\text { Woche } 37-48\end{array}$ & 5,2 & - & 4,2 & 3,3 \\
\hline $\begin{array}{l}>50 \% \text {-Res- } \\
\text { ponderrate für } \\
\text { MMD Wochen } \\
1-12\end{array}$ & $37,4 \%$ & - & $\begin{array}{l}49,8 \% \\
\text { TG }=12,4 \% \\
95 \%-C l= \\
3-21 \% \\
\text { NNT }=8,1\end{array}$ & $\begin{array}{l}56,3 \% \\
\text { TG }=18,9 \% \\
95 \%-C I= \\
10-28 \% \\
\text { NNT }=5,3\end{array}$ \\
\hline $\begin{array}{l}>50 \% \text {-Res- } \\
\text { ponderrate für } \\
\text { MMD für die } \\
\text { Wochen 37-48 }\end{array}$ & $55,4 \%$ & - & $64,7 \%$ & $69,8 \%$ \\
\hline
\end{tabular}

TG = Therapeutischer Gewinn (Differenz zwischen Verum und Placebo), NNT = Number needed to treat 
- Tab. 14 Monoklonale Antikörper in der Prophylaxe der chronischen Migräne

\begin{tabular}{|c|c|c|}
\hline & $\begin{array}{l}\text { Erenumab } \\
\text { Phase-2-Studie } \\
{[34]}\end{array}$ & $\begin{array}{l}\text { Fremanezumab } \\
\text { HALO-CM [35] }\end{array}$ \\
\hline Studienziel & $\begin{array}{l}\text { Prophylaxe der chro- } \\
\text { nischen Migräne }\end{array}$ & $\begin{array}{l}\text { Prophylaxe der chroni- } \\
\text { schen Migräne }\end{array}$ \\
\hline $\begin{array}{l}\text { Einschlusskrite- } \\
\text { rium }\end{array}$ & $\begin{array}{l}\geq 15 \text { Kopfschmerzta- } \\
\text { ge pro Monat }\end{array}$ & $\begin{array}{l}\geq 15 \text { Kopfschmerztage } \\
\text { pro Monat }\end{array}$ \\
\hline n Patienten & $n=667$ & $\mathrm{n}=1130$ \\
\hline Intervention & $\begin{array}{l}70 \mathrm{mg} \text { oder } 140 \mathrm{mg} \\
\text { pro Monat s. c. }\end{array}$ & $\begin{array}{l}225 \text { mg pro Monat } \\
\text { ( } 675 \text { mg Loading Dose) } \\
\text { oder } 675 \text { mg alle } 3 \text { Mo- } \\
\text { nate s.c. }\end{array}$ \\
\hline $\begin{array}{l}\text { Behandlungs- } \\
\text { dauer }\end{array}$ & 12 Wochen & 12 Wochen \\
\hline $\begin{array}{l}\text { Primärer End- } \\
\text { punkt }\end{array}$ & $\begin{array}{l}\text { Reduktion der Mi- } \\
\text { gränetage Wochen } \\
9-12\end{array}$ & $\begin{array}{l}\text { Reduktion der Kopf- } \\
\text { schmerztage pro Monat, } \\
\text { Wochen } 1-12\end{array}$ \\
\hline $\begin{array}{l}\text { Wichtige sekun- } \\
\text { däre Endpunkte }\end{array}$ & $\begin{array}{l}\geq 50 \% \text {-Responder- } \\
\text { rate, Einnahme von } \\
\text { Triptanen }\end{array}$ & $\begin{array}{l}\geq 50 \% \text {-Responderrate, } \\
\text { Einnahme von Akutthe- } \\
\text { rapie }\end{array}$ \\
\hline $\begin{array}{l}\text { Wichtige Aus- } \\
\text { schlusskriterien }\end{array}$ & $\begin{array}{l}\text { >3 unwirksame } \\
\text { vorhergehende } \\
\text { Therapien }\end{array}$ & $\begin{array}{l}\text { > } 2 \text { unwirksame vorher- } \\
\text { gehende Therapien }\end{array}$ \\
\hline NCT-Nummer & NCT02066415 & NCT02621931 \\
\hline
\end{tabular}

- Tab.15 Monoklonale Antikörper in der Prophylaxe der chronischen Migräne

\begin{tabular}{|c|c|c|}
\hline & $\begin{array}{l}\text { Galcanezumab RE- } \\
\text { GAIN [36] }\end{array}$ & Eptinezumab [37] \\
\hline Studienziel & $\begin{array}{l}\text { Prophylaxe der chroni- } \\
\text { schen Migräne }\end{array}$ & $\begin{array}{l}\text { Prophylaxe der chro- } \\
\text { nischen Migräne }\end{array}$ \\
\hline $\begin{array}{l}\text { Einschlusskrite- } \\
\text { rium }\end{array}$ & $\begin{array}{l}\geq 15 \text { Kopfschmerztage } \\
\text { pro Monat }\end{array}$ & $\begin{array}{l}\geq 15 \text { Kopfschmerzta- } \\
\text { ge pro Monat }\end{array}$ \\
\hline n Patienten & $\mathrm{n}=1113$ & $n=616$ \\
\hline Intervention & $\begin{array}{l}120 \mathrm{mg} \text { pro Monat } \\
\text { ( } 240 \mathrm{mg} \text { Loading Dose) } \\
\text { oder } 240 \mathrm{mg} \text { pro Monat } \\
\text { s. c. }\end{array}$ & $\begin{array}{l}1 \times 10,30,100 \text { oder } \\
300 \mathrm{mg} \text { i.v. }\end{array}$ \\
\hline $\begin{array}{l}\text { Behandlungs- } \\
\text { dauer }\end{array}$ & 3 Monate & 3 Monate \\
\hline $\begin{array}{l}\text { Primärer End- } \\
\text { punkt }\end{array}$ & $\begin{array}{l}\text { Reduktion der Migräne- } \\
\text { tage über } 3 \text { Monate }\end{array}$ & $\begin{array}{l}\geq 75 \% \text {-Responderrate } \\
\text { Woche } 1-12\end{array}$ \\
\hline $\begin{array}{l}\text { Wichtige sekun- } \\
\text { däre Endpunkte }\end{array}$ & $\begin{array}{l}\geq 50 \%-, 75 \%- \\
100 \% \text {-Responderraten, } \\
\text { MSQ }\end{array}$ & $\geq 50 \%$-Responderrate \\
\hline $\begin{array}{l}\text { Wichtige Aus- } \\
\text { schlusskriterien }\end{array}$ & $\begin{array}{l}\text { >3 unwirksame vorher- } \\
\text { gehende Therapien }\end{array}$ & $\begin{array}{l}\text { Opioide oder Barbi- } \\
\text { turate an }>4 \text { Tagen im } \\
\text { Monat }\end{array}$ \\
\hline NCT-Nummer & NCT02614261 & NCT02275117 \\
\hline
\end{tabular}

\section{Studien zur Prophylaxe der chronischen Migräne}

Bei der chronischen Migräne ist eine prophylaktische Wirkung durch methodisch solide placebokontrollierte Studien nur für OnabotulinumtoxinA und Topiramat belegt. In die beiden PREEMPT-Studien mit OnabotulinumtoxinA wurden insgesamt 1384 Patienten mit chronischer Migräne eingeschlossen [26, 27]. Im Rahmen der doppelblinden Studie wurden 2 Behandlungszyklen im Abstand von 3 Monaten untersucht, gefolgt von einer 6-monatigen offenen Behandlungsphase. In einer gepoolten Analyse [28] reduzierte OnabotulinumtoxinA im Vergleich zu Placebo signifikant die Tage mit Kopfschmerzen, die Häufigkeit der Migräneattacken, Tage mit ausgeprägten Kopfschmerzen, die kumulativen Kopfschmerzstunden pro Tag und die subjektive Beeinträchtigung. Die Anzahl der Kopfschmerztage im Monat reduzierte sich von 19,9 um 8,4 Tage in der OnabotulinumtoxinA-Gruppe und von 19,8 um 6,6 Tage in der Placebo-Gruppe. Auch bei Patienten mit Übergebrauch von Schmerz- oder Migränemitteln zeigte OnabotulinumtoxinA eine gute Wirkung [29].

Die Wirksamkeit von Topiramat in der Behandlung der chronischen Migräne konnte in 2 randomisierten placebokontrollierten Studien belegt werden. 59 Patienten wurden über 16 Wochen mit Placebo oder Topiramat $100 \mathrm{mg} /$ Tag behandelt [30]. 22\% der mit Topiramat behandelten Patienten zeigten eine mindestens $50 \%$ ige Reduktion der Kopfschmerztage/Monat (0\% in der Placebo-Gruppe, $p=0,012)[31,32]$. Die Kopfschmerztage reduzierten sich im Durchschnitt um $-3,5 \pm 6,3$ im Monat in der Verum-Gruppe und um $0,2 \pm 4,7$ in der Placebo-Gruppe $(p=0,02)$. Es zeigte sich auch eine signifikante Besserung der Kopfschmerztage $(p<0,03)$ bei den Patienten (78\%) mit Medikamentenübergebrauch (3,5 \pm 7,1 Tage). Ein ähnliches Ergebnis zeigte eine größere ( $n=306)$ amerikanische Studie [33]. In der Topiramat-Gruppe fand sich auch hier eine signifikante Reduktion $(6,4 \pm 5,8)$ der Migränetage im Vergleich zu Placebo $(4,7 \pm 6,1 ; p=0,01)$.

\section{Erenumab zur Prophylaxe der chronischen Migräne}

Erenumab wurde bei der chronischen Migräne in einer Phase-2-Studie untersucht [34]. Es handelte sich um eine randomisierte doppelblinde placebokontrollierte multizentrische Studie, in die Patienten mit chronischer Migräne in den Vereinigten Staaten und Europa eingeschlossen wurden. Die Patienten wurden im Verhältnis $3: 2$ : 2 zu subkutanem Placebo, Erenumab 70 mg oder Erenumab $140 \mathrm{mg}$ alle 4 Wochen für 12 Wochen randomisiert. Der primäre Endpunkt war die Änderung der Migränetage pro Monat von der 4-wöchigen Baseline zu den letzten 4 Wochen der doppelblinden Behandlungsphase.

Zwischen April 2014 und Dezember 2015 wurden 667 Patienten in die Studie eingeschlossen. 286 erhielten Placebo, 191 die niedrige Dosis und 190 die hohe Dosis von Erenumab. Die monatliche Reduktion der Migränetage betrug für die beiden Dosierungen von Erenumab 6,6 Tage und für Placebo 4,2 Tage. Der absolute Unterschied von minus 2,5 Tagen war signifikant. Nebenwirkungen berichteten $39 \%$ der Patienten in der Placebo-Gruppe, $44 \%$ bei der niedrigen Dosis und $47 \%$ bei der hohen Dosis von Erenumab. Die 
- Tab. 16 Prophylaxe der chronischen Migräne mit Erenumab [34]

\begin{tabular}{|c|c|c|c|}
\hline & $\begin{array}{l}\text { Placebo } \\
n=286\end{array}$ & $\begin{array}{l}\text { Erenumab } \\
70 \mathrm{mg} \\
\mathrm{n}=191\end{array}$ & $\begin{array}{l}\text { Erenumab } \\
140 \mathrm{mg} \\
\mathrm{n}=190\end{array}$ \\
\hline $\begin{array}{l}\text { Mean monthly } \\
\text { migraine days } \\
\text { (MMD) bei Studi- } \\
\text { enbeginn }\end{array}$ & 18,4 & 17,9 & 17,8 \\
\hline $\begin{array}{l}\text { Reduktion der } \\
\text { MMD von der Ba- } \\
\text { seline zu Monat } 3\end{array}$ & $-4,2$ & $-6,6$ & $-6,6$ \\
\hline $\begin{array}{l}\text { Zahl der MMD im } \\
\text { Monat } 3 \text { (\% der } \\
\text { Baseline) }\end{array}$ & $\begin{array}{l}14,2 \\
(77 \%)\end{array}$ & $11,3(63 \%)$ & 11,2 (63\%) \\
\hline $\begin{array}{l}>50 \% \text {-Respon- } \\
\text { derrate für MMD } \\
\text { Wochen 1-12 }\end{array}$ & $23 \%$ & $\begin{array}{l}40 \% \\
\text { TG }=17 \% \\
95 \%-C l=8-25 \%\end{array}$ & $\begin{array}{l}41 \% \\
\text { TG }=18 \% \\
95 \%-C l=10-27 \%\end{array}$ \\
\hline SAE & 7 & 6 & 2 \\
\hline $\begin{array}{l}\text { SAE mit Studie- } \\
\text { nabbruch }\end{array}$ & 2 & 0 & 2 \\
\hline
\end{tabular}

TG = Therapeutischer Gewinn (Differenz zwischen Verum und Placebo), SAE = schwerwiegende unerwünschte Arzneimittelwirkungen

häufigsten Nebenwirkungen waren Schmerz an der Injektionsstelle, Übelkeit und Infektion der oberen Atemwege. Bei 11 Patienten in der Niedrigdosisgruppe und bei 3 Patienten in der Hochdosisgruppe ließen sich Autoantikörper gegen Erenumab nachweisen. Im Bereich der Laborwerte oder des EKGs fanden sich keine Auffälligkeiten.

Der CGRP-Rezeptorantikörper Erenumab ist in beiden Dosierungen von 70 und 140 mg wirksamer als Placebo für die Reduktion der Migränetage bei Patienten mit chronischer Migräne.

\section{Fremanezumab zur Prophylaxe der chronischen Migräne}

Bei der HALO-Studie handelte es sich um eine randomisierte, placebokontrollierte Studie an Patienten mit chronischer Migräne, bei denen die Patienten in 3 Therapiegruppen eingeteilt wurden [35]. Die erste Therapiegruppe erhielt eine initiale Dosis von 675 mg Fremanezumab und Placebo subkutan nach 4 und 8 Wochen. In der zweiten Gruppe erhielten die Patienten initial 675 mg Fremanezumab und 225 mg nach 4 und 8 Wochen, in der dritten Gruppe Placebo. Der primäre Endpunkt war die mittlere Änderung der Kopfschmerztage pro Monat, wobei diese definiert wurden als Tage mit Kopfschmerzen, die mindestens 4 Stunden anhielten, die eine Intensität von mindestens moderat hatten oder mit spezifischer Migränemedikation wie Triptanen oder Mutterkornalkaloiden behandelt wurden. Berechnet wurde die Häufigkeit von Kopfschmerztagen pro Monat über 12 Wochen.

\section{Ergebnisse}

Es wurden insgesamt 1130 Patienten eingeschlossen. 376 erhielten Fremanezumab einmalig, 379 monatlich und 375 Placebo.
- Tab. 17 Fremanezumab zur Prophylaxe der chronischen Migräne [35]

\begin{tabular}{|c|c|c|c|}
\hline & $\begin{array}{l}\text { Placebo } \\
n=375\end{array}$ & $\begin{array}{l}\text { Fremanezu- } \\
\text { mab } \\
1 \times 3 \text { Monate } \\
n=376\end{array}$ & $\begin{array}{l}\text { Fremanezu- } \\
\text { mab } \\
1 \times \text { Monat } \\
\mathrm{n}=379\end{array}$ \\
\hline $\begin{array}{l}\text { Mean monthly } \\
\text { migraine days } \\
\text { (MMD) bei Studien- } \\
\text { beginn }\end{array}$ & 16,4 & 16,2 & 16,0 \\
\hline $\begin{array}{l}\text { Reduktion der MMD } \\
\text { von der Baseline zu } \\
\text { Monat } 3\end{array}$ & $-3,6$ & $-5,2$ & $-5,3$ \\
\hline $\begin{array}{l}\text { Zahl der MMD im } \\
\text { Monat } 3 \\
\text { (\% der Baseline) }\end{array}$ & $\begin{array}{l}12,8 \\
(80 \%)\end{array}$ & $11,0(70 \%)$ & 10,7 (69\%) \\
\hline $\begin{array}{l}>50 \% \text {-Responderra- } \\
\text { te für MMD Wochen } \\
1-12\end{array}$ & $18 \%$ & $\begin{array}{l}38 \% \\
\text { TG }=20 \% \\
95 \%-C l=14- \\
26 \% \\
\text { NNT = 5,0 }\end{array}$ & $\begin{array}{l}41 \% \\
\text { TG }=23 \% \\
95 \%-C I=16- \\
29 \% \\
\text { NNT = } 4,3\end{array}$ \\
\hline SAE & 6 & 3 & 5 \\
\hline $\begin{array}{l}\text { AE mit Studienab- } \\
\text { bruch }\end{array}$ & 8 & 5 & 7 \\
\hline \multicolumn{4}{|c|}{$\begin{array}{l}\text { TG = Therapeutischer Gewinn = Differenz zwischen Verum und } \\
\text { Placebo, NNT = Number needed to treat, } \mathrm{SAE}=\text { schwerwiegende } \\
\text { unerwünschte Arzneimittelwirkungen, } \mathrm{AE}=\text { unerwünschte Arznei- } \\
\text { mittelwirkungen }\end{array}$} \\
\hline
\end{tabular}

Die Patienten waren im Mittel 41 Jahre alt und $88 \%$ waren Frauen. 20 \% nahmen eine Migräneprophylaxe ein. 30 \% hatten Erfahrung mit Topiramat und $15 \%$ mit Botulinumtoxin. Die mediane Zeit der Kopfschmerztage in der Baseline betrug 13 Tage und die Zahl der Tage mit jedweder Kopfschmerzintensität 20 Tage. 16 Migränetage wurden in der Baseline beobachtet, an 13 Tagen wurden Medikamente zur Behandlung der Kopfschmerzen eingenommen und an 11 Tagen spezifische Migränemittel. Die mittlere Reduktion der Kopfschmerztage pro Monat betrug 4,3 nach der einmaligen Gabe von Fremanezumab, 4,6 mit der monatlichen Gabe und 2,5 mit Placebo. Dieser Unterschied zu Placebo war statistisch signifikant. Die $50 \%$-Responderrate betrug $38 \%$ und $41 \%$ für Fremanezumab und $18 \%$ für Placebo. Unerwünschte Arzneimittelwirkungen waren vergleichbar ausgeprägt. Bei 5 Patienten kam es unter Fremanezumab und bei 3 Patienten in der Placebo-Gruppe zu einem Anstieg der Leberenzyme.

\section{Galcanezumab zur Prophylaxe der chronischen Migräne}

Bei der REGAIN-Studie handelte es sich um eine randomisierte, doppelblinde, placebokontrollierte Studie bei Patienten mit chronischer Migräne [36]. Die Studie hatte eine dreimonatige doppelblinde placebokontrollierte Phase und eine neunmonatige Phase mit offener Therapie. Eingeschlossen wurden Patienten mit chronischer Migräne im Alter zwischen 18 und 65 Jahren, die im Verhält- 
nis $2: 1: 1$ zu Placebo ( $n=558)$, Galcanezumab $120 \mathrm{mg}$ mit einer initialen Dosis von $240 \mathrm{mg}(\mathrm{n}=278$ ) oder $240 \mathrm{mg}$ Galcanezumab $(n=277)$ randomisiert wurden. Die Behandlung erfolgte einmal monatlich. Der primäre Endpunkt war die Reduktion der monat-

- Tab. 18 Galcanezumab zur Prophylaxe der chronischen Migräne [38]

\begin{tabular}{|l|l|l|l|}
\hline & $\begin{array}{l}\text { Placebo } \\
\mathbf{n = 5 5 8}\end{array}$ & $\begin{array}{l}\text { Galcanezumab } \\
\mathbf{1 2 0} \mathbf{~ m g} \\
\mathbf{n = 2 7 8}\end{array}$ & $\begin{array}{l}\text { Galcanezumab } \\
\mathbf{2 4 0} \mathbf{~} \mathbf{n}\end{array}$ \\
$\mathbf{n = 2 7 7}$
\end{tabular}

TG = Therapeutischer Gewinn = Differenz zwischen Verum und Placebo, NNT = Number needed to treat, $\mathrm{SAE}=$ schwerwiegende unerwünschte Arzneimittelwirkungen, $A E=$ unerwünschte Arzneimittelwirkungen, NA= Daten nicht verfügbar lichen Migränetage während der 3-monatigen doppelblinden Behandlungsphase, verglichen mit der Baseline.

Die Patienten waren im Mittel 39-42 Jahre alt, wobei die Gruppe, die mit Galcanezumab 120 mg behandelt wurde, signifikant jünger war als die Placebo-Gruppe. 85\% der Studienteilnehmer waren Frauen. Die Migräne bestand im Mittel seit 21 Jahren und die mittlere Zahl der Migränetage pro Monat während der Baseline betrug 19,4. Die mittlere Zahl der Kopfschmerztage pro Monat betrug 21. $78 \%$ der Patienten hatten bereits Erfahrung mit einer prophylaktischen Therapie und bei $31 \%$ der Patienten hatten in der Vergangenheit bereits 2 oder mehr prophylaktische Behandlungen versagt. Bei $64 \%$ der Patienten bestand ein Übergebrauch von Schmerz- und Migränemitteln. Unter Galcanezumab kam es zu einer signifikant größeren Reduktion der Zahl der Migränetage pro Monat, verglichen mit Placebo. Die Reduktion der Migränetage pro Monat betrug unter Placebo 2,7, unter der niedrigeren Dosis von Galcanezumab 4,8 und unter der höheren Dosis 4,6. Die 50\%-Responderrate betrug 15,4\% unter Placebo, 27,6\% unter der niedrigen und 27,5\% unter der hohen Dosis von Galcanezumab. Auch für die verwendeten Lebensqualität-Instrumente ergab sich eine signifikante Überlegenheit von Galcanezumab. Galcanezumab wurde sehr gut vertragen. Die häufigsten Nebenwirkungen waren Schmerzen an der Injektionsstelle und respiratorische Infekte, die allerdings zwischen den 3 Therapiegruppen nicht unterschiedlich waren.

Galcanezumab ist bei Patienten mit chronischer Migräne signifikant besser wirksam als Placebo. Die Verträglichkeit ist sehr gut.

\section{Eptinezumab zur Prophylaxe der chronischen Migräne}

Eptinezumab wurde in einer doppelblinden, randomisierten, Placebo-kontrollierten Phase-2b-Studie an 616 Patienten mit chronischer Migräne untersucht [37]. Die Patienten wurden zu einer Injektion mit Eptinezumab 300 mg, 100 mg, 30 mg, 10 mg oder Placebo randomisiert. Der primäre Endpunkt war der Prozentsatz der

- Tab. 19 Eptinezumab bei chronischer Migräne [37]

\begin{tabular}{|c|c|c|c|c|c|}
\hline & $\begin{array}{l}\text { Placebo } \\
\mathrm{n}=121\end{array}$ & $\begin{array}{l}\text { Eptinezumab } 10 \mathrm{mg} \\
\mathrm{n}=130\end{array}$ & $\begin{array}{l}\text { Eptinezumab } 30 \mathrm{mg} \\
\mathrm{n}=122\end{array}$ & $\begin{array}{l}\text { Eptinezumab } \\
100 \mathrm{mg} \\
\mathrm{n}=122\end{array}$ & $\begin{array}{l}\text { Eptinezumab } \\
300 \mathrm{mg} \\
\mathrm{n}=121\end{array}$ \\
\hline $\begin{array}{l}\text { Mean monthly migraine } \\
\text { days (MMD) bei Studien- } \\
\text { beginn }\end{array}$ & 16,4 & 16,4 & 16,2 & 16,9 & 16,5 \\
\hline $\begin{array}{l}\text { Reduktion der MMD von } \\
\text { der Baseline zu Woche } 12\end{array}$ & $-6,1$ & $-6,7$ & $-7,9$ & $-7,6$ & $-8,2$ \\
\hline $\begin{array}{l}\text { Zahl der MMD im Monat } 3 \\
\text { (\% der Baseline) }\end{array}$ & $10,3(63 \%)$ & $9,7(59 \%)$ & $8,3(51 \%)$ & $9,3(55 \%)$ & $8,3(50 \%)$ \\
\hline $\begin{array}{l}>50 \% \text {-Responderrate für } \\
\text { MMD Wochen 1-12 }\end{array}$ & $40,5 \%$ & $\begin{array}{l}43,9 \% \\
\mathrm{TG}=3,4 \%\end{array}$ & $\begin{array}{l}55,6 \% \\
\mathrm{TG}=15,1 \%\end{array}$ & $\begin{array}{l}55,1 \% \\
\mathrm{TG}=14,6 \%\end{array}$ & $\begin{array}{l}57 \% \\
\text { TG }=16,5 \%\end{array}$ \\
\hline SAE & $17(14,0 \%)$ & $21(16,2 \%)$ & $18(14,8 \%)$ & $24(19,8 \%)$ & $21(17,4 \%)$ \\
\hline AE mit Studienabbruch & 0 & 0 & 4 & 2 & 4 \\
\hline
\end{tabular}






Patienten mit einem Rückgang der monatlichen Migränetage um 75 \% in den Wochen 1-12 im Vergleich zum 28-tägigen Screeningzeitraum. Die 75 \%igen Responderraten über die Wochen 1-12 für Eptinezumab $300 \mathrm{mg}, 100 \mathrm{mg}, 30 \mathrm{mg}$ und $10 \mathrm{mg}$ betrugen $33,3 \%$, $31,4 \%, 28,2$ \% bzw. 26,8 \% gegenüber 20,7 \% für Placebo ( $p=0,033$, $0,072,0,201,0,294$ vs. Placebo). Eptinezumab wurde gut vertragen und die Nebenwirkungsraten waren ähnlich wie bei Placebo.

\section{Leitlinien zum Einsatz von monoklonalen}

\section{Antikörpern zur Prophylaxe der Migräne}

Die Leitlinie der European Headache Federation empfiehlt den Einsatz von monoklonalen Antikörpern bei Patienten mit episodischer oder chronischer Migräne, bei denen mindestens 2 der üblichen medikamentösen Therapien versagt haben oder die aufgrund von Komorbiditäten, Nebenwirkungen oder mangelnder Compliance andere präventive Maßnahmen nicht durchführen können [39]. Nach dieser Leitlinie sollte bei Patienten mit episodischer Migräne vor dem Einsatz von monoklonalen Antikörpern eine eventuell vorbestehende medikamentöse Therapie beendet werden. Für diese Empfehlung gibt es allerdings keine Daten. Bei Patienten, die unter einer chronischen Migräne leiden, können die Antikörper zur bestehenden Therapie hinzugefügt werden. Bei Patienten mit episodischer oder chronischer Migräne wird empfohlen, die Behandlung mit monoklonalen Antikörpern nach 6 bis 12 Monaten zu beenden.

Die Amerikanische Kopfschmerzgesellschaft hat nur Empfehlungen, aber keine Leitlinien herausgegeben [1]. Die Kriterien für die Beurteilung des Therapieerfolgs sind diesen Empfehlungen entnommen.

\section{Vergleich der Wirksamkeit der monoklona-} len Antikörper bei der episodischen und der chronischen Migräne

Ein direkter Vergleich der einzelnen monoklonalen Antikörper untereinander ist nicht möglich, da es keine direkten Vergleichsstudien gibt. Es gibt auch keine Vergleichsstudien zu den bisher verfügbaren Medikamenten zur Migräneprophylaxe. Allerdings ist anzumerken, dass Antikörper gegen Liganden oder Rezeptoren unterschiedliche Kaskaden beeinflussen können und es vielleicht aus biologischen Gründen im Einzelfall sinnvoll sein kann, bei Versagen eines CGRP-Rezeptorantagonisten es mit einem CGRP-Antagonisten und vice versa zu versuchen.

Die Abb. 2-Abb. 5 zeigen die Abnahme der monatlichen Migränetage und die $50 \%$-Responderraten für die Phase-3-Studien zur episodischen und zur chronischen Migräne. Die Abb. 6 und Abb. 7 zeigen den therapeutischen Gewinn der einzelnen Studien. Es muss aber berücksichtigt werden, dass ein direkter Vergleich der einzelnen Substanzen nicht möglich ist, da unterschiedliche Methoden zur Berechnung der Reduktion der Migränetage und der $50 \%$-Responderraten angewendet wurden.

\section{Besondere Populationen und Fragestellungen Vorheriges Versagen der Migräneprophylaxe}

Der Stellenwert der CGRP-(Rezeptor-)Antikörper bei Patienten, die auf eine herkömmliche Prophylaxe nicht angesprochen haben, wurde in mehreren Studien und Subgruppenanalysen untersucht. In einigen Zulassungsstudien wurden auch Patienten eingeschlossen, die bei episodischer und chronischer Migräne auf frühere prophylaktische Behandlungen in ausreichender Dosierung und Behandlungsdauer nicht angesprochen hatten. 


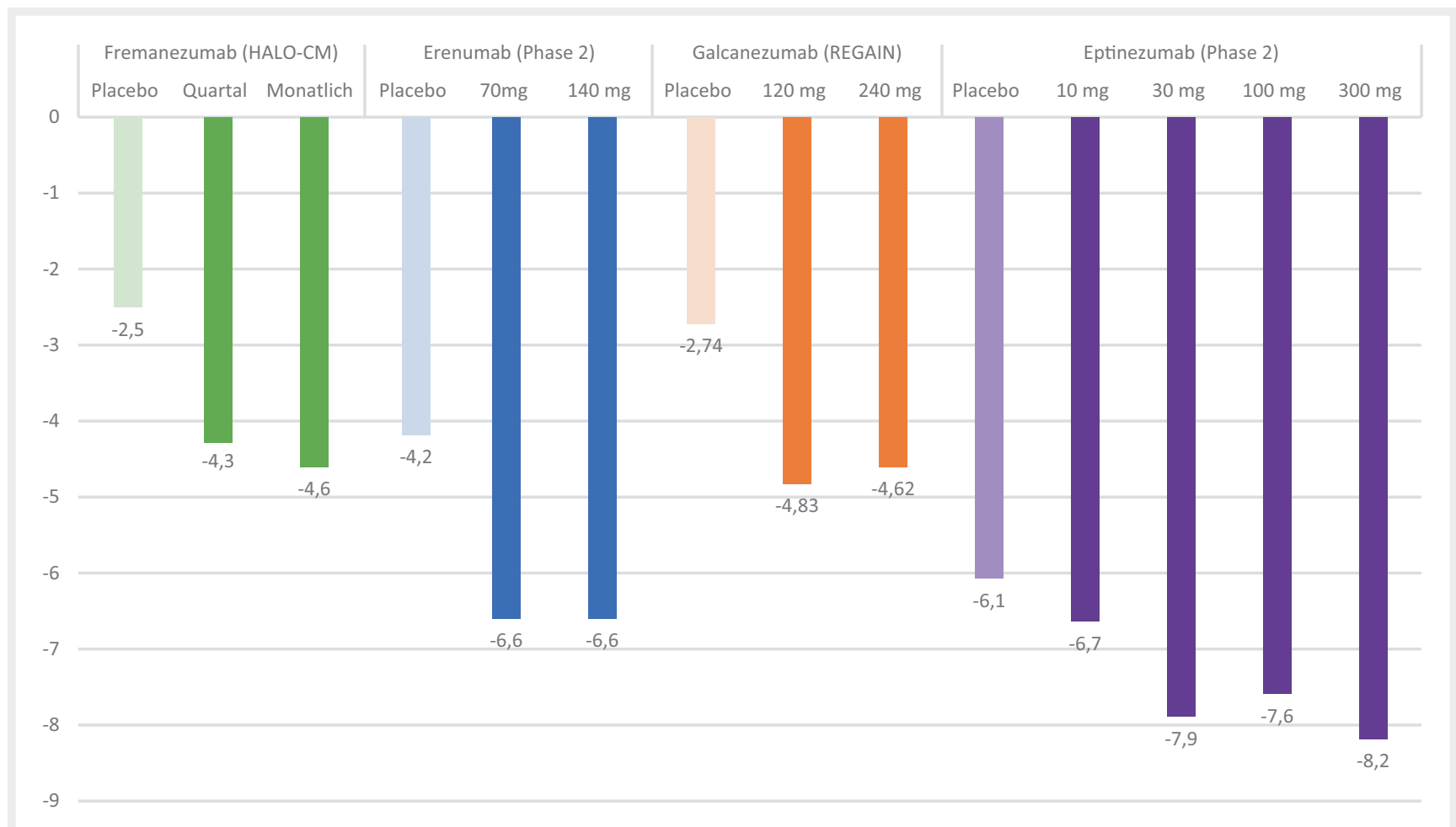

- Abb.3 Abnahme der monatlichen Migränetage bei chronischer Migräne

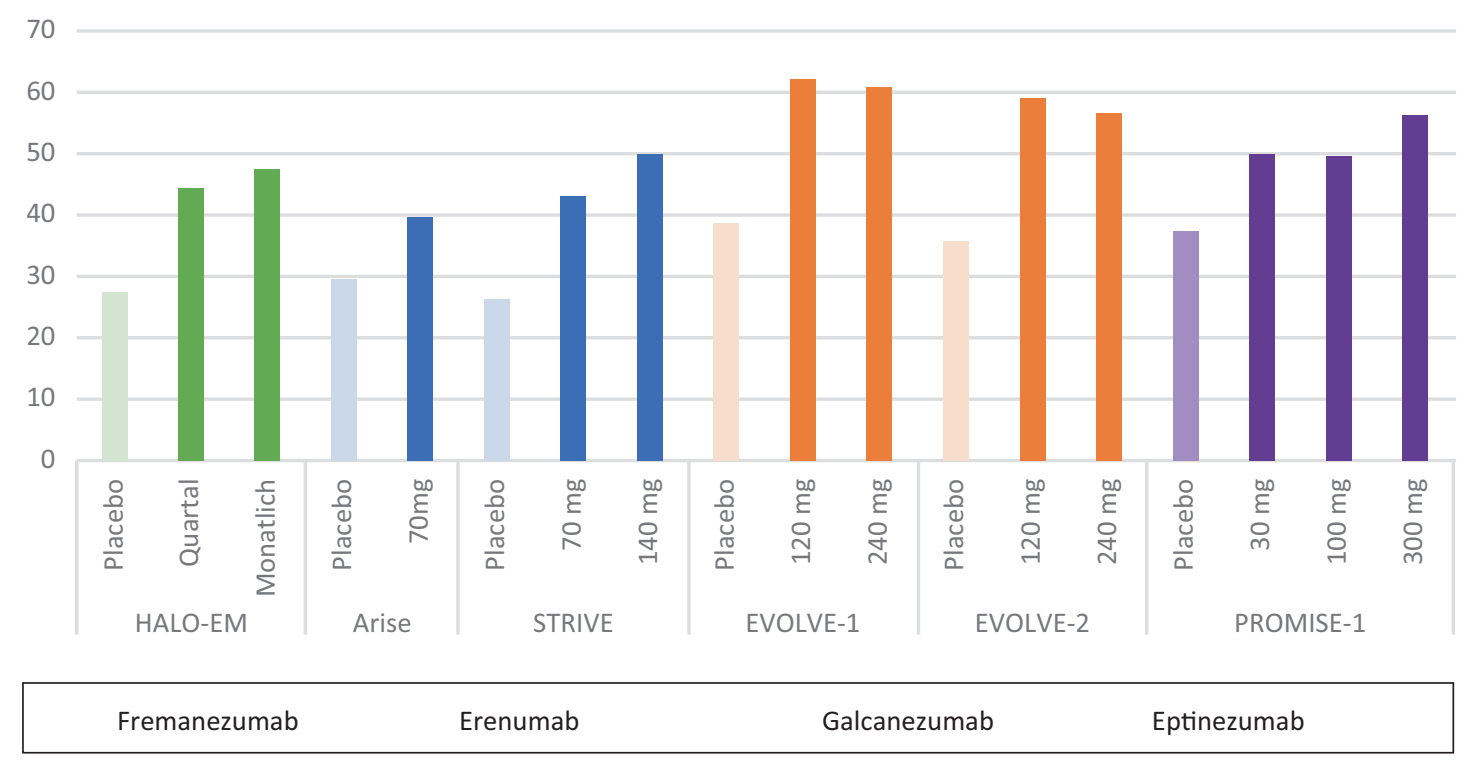

- Abb.4 50\%-Responderrate für Migränetage pro Monat in Studien mit episodischer Migräne

Die LIBERTY-Studie untersuchte als primäres Studienziel das Ansprechen auf $140 \mathrm{mg}$ Erenumab bei Patienten mit therapierefraktärer episodischer Migräne ohne begleitenden Medikamentenübergebrauch in einem randomisierten, doppelblinden, placebokontrollierten Studiendesign [40]. Das wesentliche Einschlusskriterium für die Studie war, dass die Patienten innerhalb der vorangegangenen 5 Jahre auf 2 bis 4 der folgenden Substanzen nicht respondiert hatten und/oder sie nicht vertragen hatten: Propranolol oder Metoprolol, Topiramat, Flunarizin, Valproat, Amitriptylin, Venlafaxin, Lisinopril, Candesartan oder eine andere lokal zugelassene Prophylaxe wie Cinnarizin, Indoramin, Oxeteron, Nadolol und Pizotifen. Mindestens eine der fehlgeschlagenen Therapien musste mit Propranolol, Metoprolol, Topiramat oder Flunarizin erfolgt sein. Für Valproat musste entweder die unzureichende Wirkung nach- 


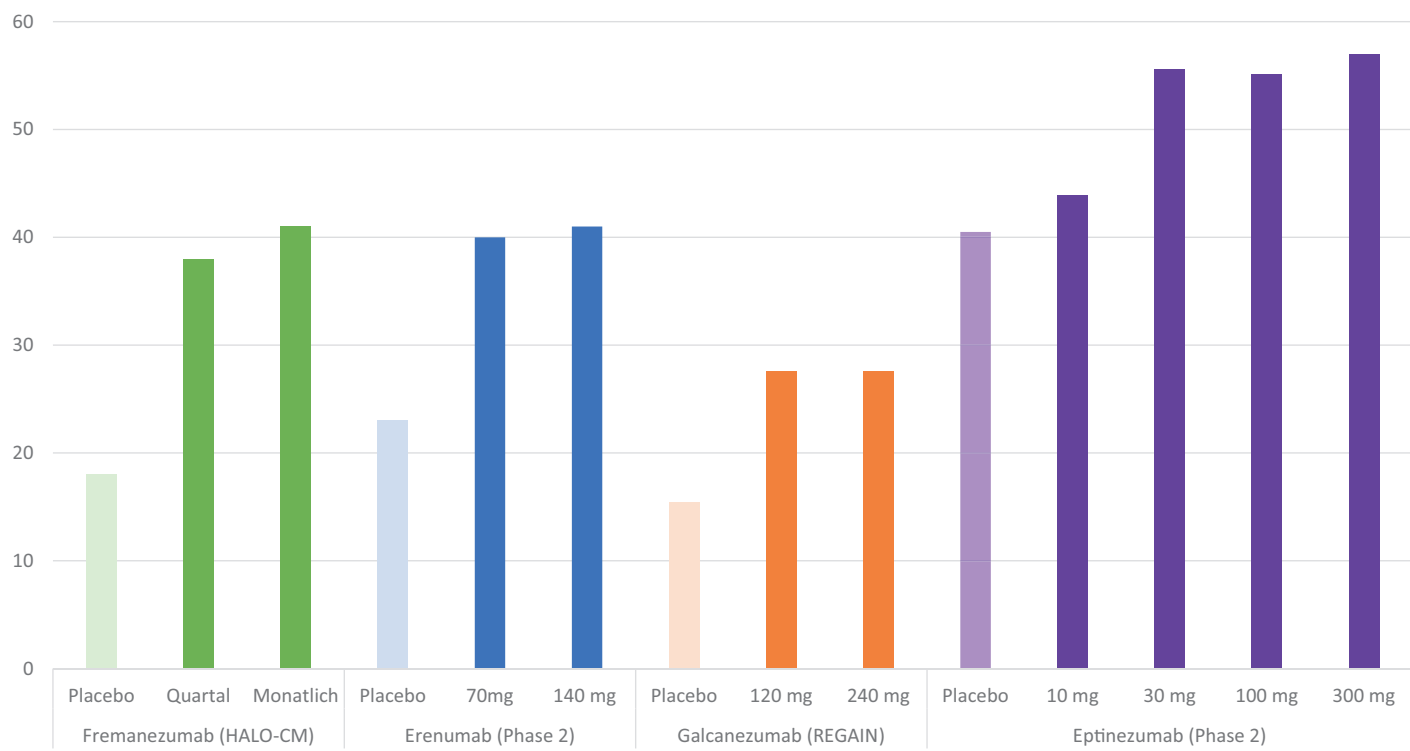

- Abb.5 50\%-Responderrate für Migränetage pro Monat in Studien mit chronischer Migräne

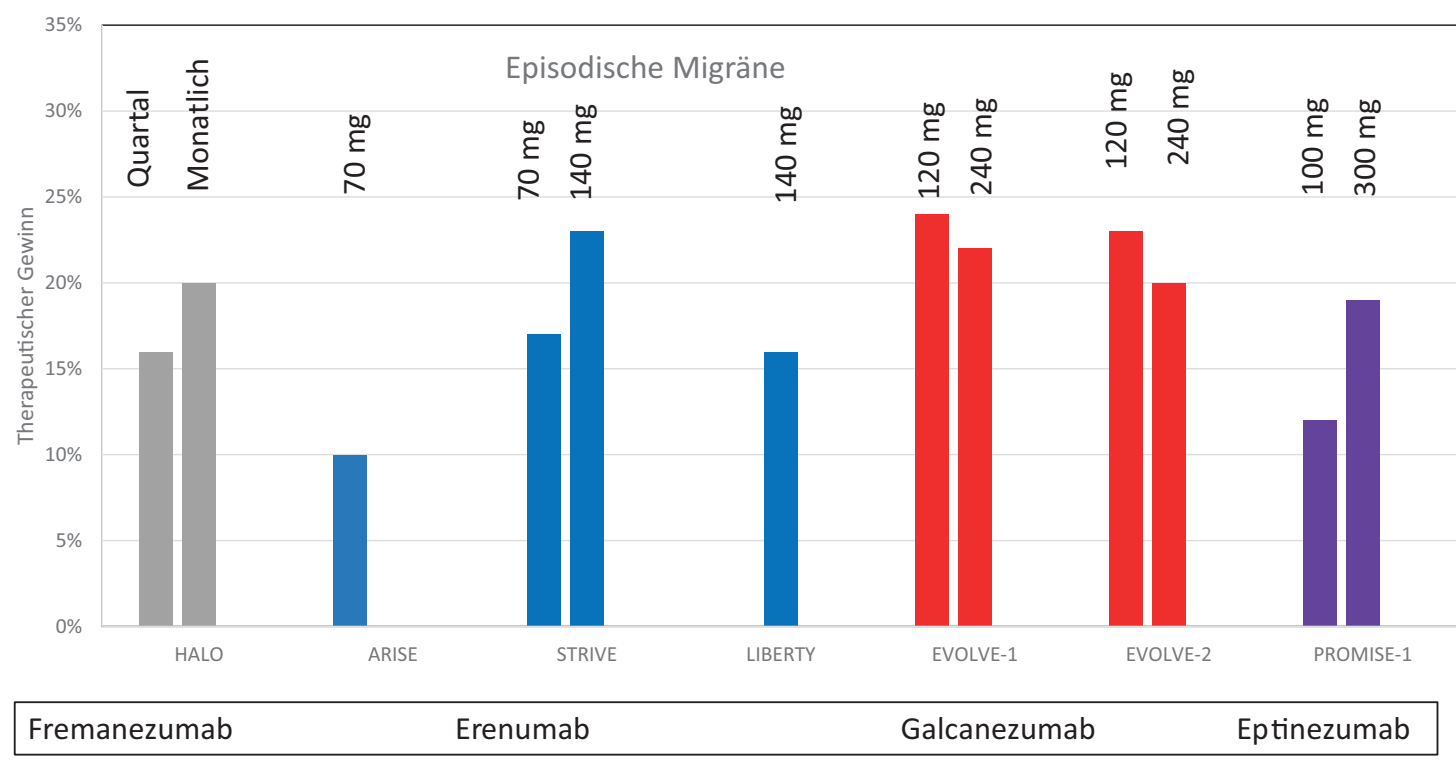

- Abb. 6 Therapeutischer Gain (Verum minus Placebo) in Prozent bei der Prophylaxe der episodischen Migräne

gewiesen sein oder eine Kontraindikation vorliegen. Eine unzureichende Wirkung setzte eine ausreichend lange Behandlungsdauer von mindestens 2-3 Monaten voraus. Als Unverträglichkeit war jedes Absetzen der Medikation aufgrund von Nebenwirkungen definiert. Die weiteren Ein- und Ausschlusskriterien entsprachen im Wesentlichen denen der bereits vorgestellten Zulassungsstudien.

121 Patienten erhielten Erenumab, 125 Patienten erhielten Placebo. In beiden Behandlungsgruppen schieden jeweils 3 Patienten vorzeitig aus. Die Studienpopulation war in beiden Behandlungsarmen ausbalanciert. In beiden Armen hatten $70 \%$ der Patienten eine hochfrequente episodische Migräne mit 8-14 Migränetagen pro Monat. Eine unzureichende Wirkung auf 2, 3 bzw. 4 Substanzen war in der Verum-Gruppe bei $36 \%$, 36\% bzw. 27\% gegeben und in der Placebo-Gruppe bei $42 \%$, 39\% bzw. 18\%. Die in der Vergangenheit am häufigsten ohne Erfolg eingesetzten Substanzen waren in absteigender Häufigkeit: Topiramat, Propranolol, Amitriptylin, Metoprolol und Valproat. Der primäre Endpunkt - eine mindestens 50 \%ige Abnahme der Migränetage im 3. Behandlungsmonat im Vergleich zur Baseline - wurde in der Erenumab-Gruppe von 30\% 


\section{Chronische Migräne}

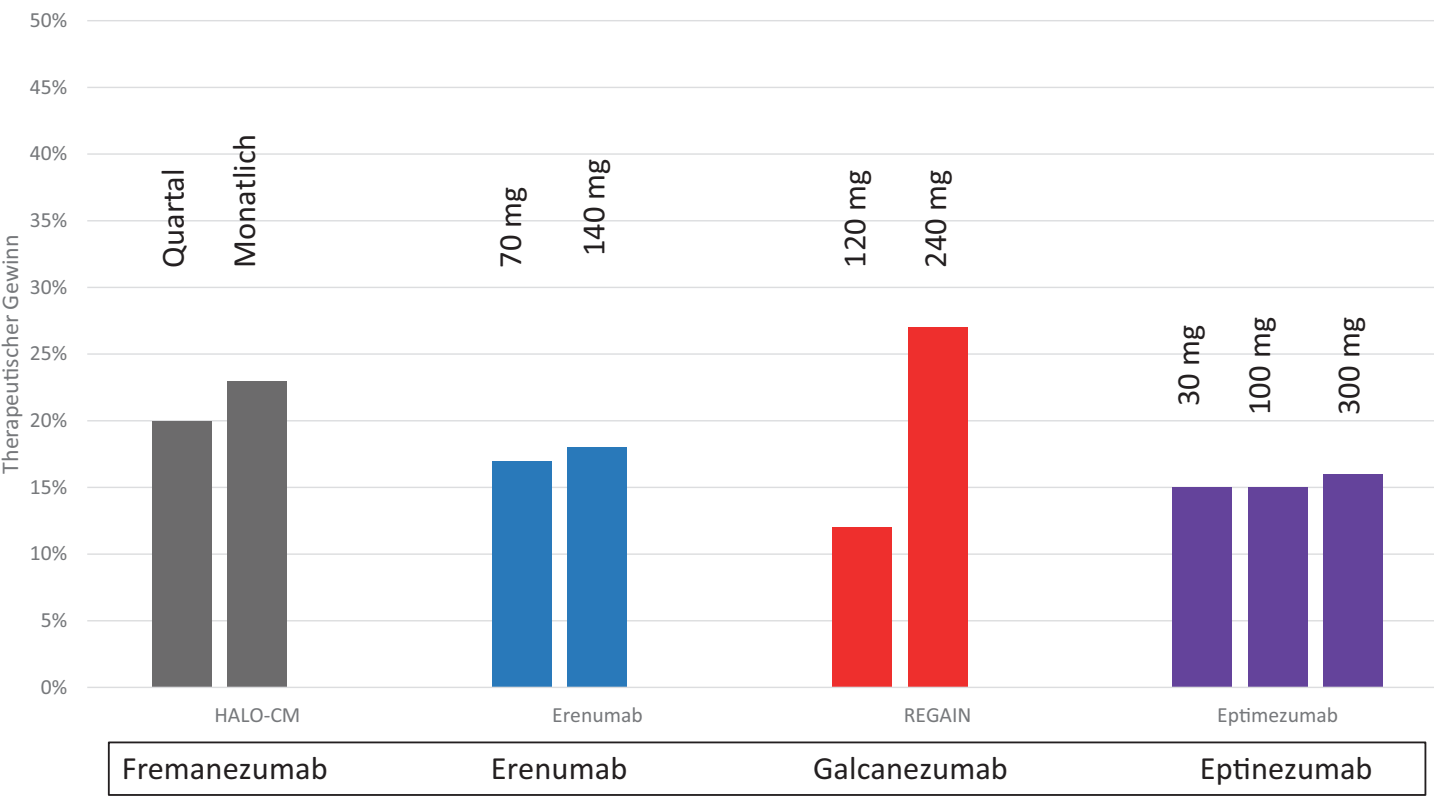

Abb.7 Therapeutischer Gain (Verum minus Placebo) für die 50\%-Responderrate in Prozent bei der Prophylaxe der chronischen Migräne

> Tab. 20 Subgruppenanalyse: Erenumab 70/140 mg vs. Placebo zur Prophylaxe der chronischen Migräne bei Patienten mit/ohne vorangegangene erfolglose Therapie

\begin{tabular}{|c|c|c|c|}
\hline & $\begin{array}{l}\text { keine erfolglose Therapie } \\
\text { Placebo/Erenumab } 70 \mathrm{mg} / \\
\text { Erenumab } 140 \mathrm{mg}\end{array}$ & $\begin{array}{l}\geq 1 \text { erfolglose Therapie } \\
\text { Placebo/Erenumab } 70 \mathrm{mg} / \\
\text { Erenumab } 140 \mathrm{mg}\end{array}$ & $\begin{array}{l}\geq 2 \text { erfolglose Therapien } \\
\text { Placebo/Erenumab } 70 \mathrm{mg} / \\
\text { Erenumab } 140 \mathrm{mg}\end{array}$ \\
\hline $\begin{array}{l}\text { Mean monthly migraine days (MMD) } \\
\text { bei Studienbeginn }\end{array}$ & $17,5 / 17,1 / 17,2$ & $17,1 / 18,2 / 18,1$ & $17,2 / 18,0 / 18,8$ \\
\hline $\begin{array}{l}\text { Reduktion der MMD von der Baseline } \\
\text { zu Monat } 3\end{array}$ & $-5,7 \mid-7,9 /-6,1$ & $-3,5 /-6,0 /-6,8$ & $-2,7|-5,4|-7,0$ \\
\hline $\begin{array}{l}>50 \% \text {-Responderrate für MMD } \\
\text { Wochen } 1-12\end{array}$ & $38,1 \% / 50 \% / 41,9 \%$ & $17,3 \% / 34,7 \% / 40,8 \%$ & $14,2 \% / 35,6 \% / 41,3 \%$ \\
\hline SAE n (\%) & $2(2,4 \%) / 3(4,7 \%) / 0$ & $\begin{array}{l}5(2,5 \%) / 3(2,4 \%) / \\
2(1,6 \%)\end{array}$ & $\begin{array}{l}4(2,8 \%) / 3(3,3 \%) / \\
1(1,1 \%)\end{array}$ \\
\hline
\end{tabular}

der Patienten erreicht und in der Placebo-Gruppe von 14\% (OR 2,7 $[96 \%-\mathrm{Cl}=1,4-5,2])$.

Es wurden auch alle sekundären Endpunkte erreicht: Es wurde ein signifikanter Rückgang der monatlichen Migränetage in Woche 1-4 (im Mittel -1,8 Tage vs. 0,1 unter Placebo), Woche 5-8 (-2,3 vs. 0,1 Tage) und in Woche $9-12$ (-1,8 vs. $-0,2$ Tage) erzielt. Es kam in den 3 jeweils 4-wöchigen Behandlungsintervallen zu einer signifikanten Abnahme der Tage, an denen Akutmedikation eingenommen wurde, und es konnte ein signifikanter Rückgang der Beeinträchtigung körperlicher Funktionen (MPFIT) und der allgemeinen Beeinträchtigung durch Kopfschmerz (HIT-6) dokumentiert werden.
Mit dieser Studie wurde für Erenumab gezeigt, dass in der 140-mg-Dosierung auch bei Patienten mit erwiesener Therapieresistenz bzw. Therapieunverträglichkeit von 2-4 Vorbehandlungen eine signifikante prophylaktische Wirkung bei sehr guter Verträglichkeit erreicht werden kann. Auch in dieser Patientenpopulation wurde der Wirkbeginn von Erenumab bereits innerhalb der ersten 4 Behandlungswochen nachgewiesen. Anhand dieser Daten kann die Gabe von Erenumab bei Patienten mit episodischer Migräne ohne begleitenden Medikamentenübergebrauch mit vorbestehenden Unverträglichkeiten und unzureichendem Ansprechen auf Standardprophylaktika empfohlen werden.

Für Patienten mit therapierefraktärer chronischer Migräne liegt eine Subgruppenanalyse der Phase-2-Studie von Erenumab bei der 
- Tab. 21 Subgruppenanalyse: Galcanezumab 120 mg (nach 1 Loading Dose von 240 mg) vs. Galcanezumab 240 mg vs. Placebo zur Prophylaxe der chronischen Migräne bei Patienten mit/ohne vorangegangene erfolglose Therapie

\begin{tabular}{|c|c|c|c|}
\hline & $\begin{array}{l}\text { keine erfolglose Vortherapie } \\
\text { Placebo/Galcanezumab } 120 \mathrm{mg} / \\
\text { Galcanezumab } 240 \mathrm{mg}\end{array}$ & $\begin{array}{l}\geq 1 \text { erfolglose Therapie } \\
\text { Placebo/Galcanezumab } 120 \mathrm{mg} / \\
\text { Galcanezumab } 240 \mathrm{mg}\end{array}$ & $\begin{array}{l}\geq 2 \text { erfolglose Therapien } \\
\text { Placebo/Galcanezumab } 120 \mathrm{mg} / \\
\text { Galcanezumab } 240 \mathrm{mg}\end{array}$ \\
\hline $\begin{array}{l}\text { Mean monthly migraine days (MMD) } \\
\text { bei Studienbeginn }\end{array}$ & $19,6 / 18,8 / 19,3$ & $19,5 / 20,0 / 19,1$ & $19,6 / 20,0 / 19,0$ \\
\hline $\begin{array}{l}\text { Abnahme des Least-Square-Mittel- } \\
\text { werts der MMDüber } 3 \text { Monate }\end{array}$ & $-4,28 /-4,88 /-6,58$ & $-2,02 /-5,53 /-3,53$ & $-1,01 /-5,35 /-2,77$ \\
\hline $\begin{array}{l}>50 \% \text {-Responderrate für MMD } \\
\text { Wochen } 1-12\end{array}$ & $19,9 \% / 23,9 \% / 35,4 \%$ & $11,3 \% / 31,2 \% / 20,5 \%$ & $9,4 \% / 29,6 \% / 18,7 \%$ \\
\hline
\end{tabular}

chronischen Migräne vor [41]. Dabei wurde die monatliche Gabe von 70 bzw. $140 \mathrm{mg}$ Erenumab versus Placebo in der Subgruppe der Patienten, die auf prophylaktische Behandlungen mit Substanzen aus mindestens 1 oder 2 Substanzkategorien nicht respondiert hatten, im Vergleich zu Patienten ohne Versagen auf eine Prophylaxe analysiert. Von den insgesamt 667 Patienten hatten 492 Patienten in der Vergangenheit eine Prophylaxe erhalten. Von diesen hatten 360 nicht respondiert und 326 die Behandlung wegen Nebenwirkungen nicht toleriert. Am häufigsten waren Topiramat ( $n=299)$, Betarezeptorenblocker $(n=231)$ und trizyklische Antidepressiva ( $n=209$ ) ohne Erfolg eingesetzt worden. Es wurden 3 Subgruppen gebildet: Patienten, die bislang nicht oder mit Erfolg vorbehandelt waren (Gruppe 1), Patienten mit Unverträglichkeit oder Therapieversagen auf mindestens 1 (Gruppe 2) bzw. auf mindestens 2 Substanzklassen (Gruppe 3). Patienten der Gruppe 1 waren weniger lang erkrankt, hatten weniger Tage mit Einnahme von migränespezifischer Akutmedikation und seltener einen Medikamentenübergebrauch als die beiden anderen Subgruppen. Numerisch nahmen die monatlichen Migränetage in allen Subgruppen unter Behandlung mit Erenumab stärker ab als unter Behandlung mit Placebo. Bei den Gruppen mit erfolglosen Vorbehandlungen war die 140-mg-Dosis durchweg effektiver als die 70-mg-Dosis und die Placebo-Ansprechrate geringer als bei Patienten ohne vorangegangenes Therapieversagen. Unerwünschte Ereignisse wurden in der Gruppe ohne Therapieversagen etwas seltener (30,6-37,5\%) berichtet als in den Gruppen mit vorangegangenem Therapieversagen (42,2-60,0\%). Signifikante Unterschiede im Vergleich zur jeweiligen Gruppe, die mit Placebo behandelt wurde, traten jedoch nicht auf.

Es liegt auch eine Subgruppenanalyse der REGAIN-Studie vor, in der Patienten mit chronischer Migräne im Alter zwischen 18 und 55 Jahren im Verhältnis $2: 1: 1$ zu Placebo $(n=558)$, Galcanezumab $120 \mathrm{mg}$ mit einer initialen Dosis von $240 \mathrm{mg}(\mathrm{n}=387)$ oder $240 \mathrm{mg}$ Galcanezumab ( $\mathrm{n}=277$ ) randomisiert wurden [39]. Die Behandlung erfolgte einmal monatlich. Dabei wurden die beiden Dosierungen von Galcanezumab versus Placebo in der Subgruppe der Patienten, die auf prophylaktische Behandlungen mit mindestens 1 oder mindestens 2 prophylaktisch wirksamen Substanz(en) (Empfehlungsgrad A und B der American Academy of Neurology/ American Headache Society) einschließlich Onabotulinumtoxin nicht respondiert hatten, im Vergleich zu Patienten ohne Versagen auf eine Prophylaxe analysiert. Von den insgesamt 1113 Pati- enten hatten in den vorangegangenen 5 Jahren 573 auf mindestens 1 Substanz, 356 auf mindestens 2 Substanzen und 199 auf mindestens 3 Substanzen nicht respondiert oder die Therapie wegen Unverträglichkeiten nicht toleriert. Am häufigsten waren Topiramat (57,6\%), Amitriptylin (31,4\%), Propranolol (26,7\%) und Onabotulinumtoxin (17,3\%) ohne Erfolg eingesetzt worden. Bei 63,8\% des Gesamtkollektivs waren die Kriterien für einen Medikamentenübergebrauchskopfschmerz erfüllt. Es wurden 3 Subgruppen gebildet: Patienten ohne Therapieversagen in der Vorgeschichte, Patienten mit Unverträglichkeit oder Therapieversagen von mindestens 1 bzw. von mindestens 2 Substanzklassen. Die Behandlung mit Galcanezumab war in allen 3 Gruppen über die gesamten 3 Monate in beiden Dosierungen einer Placebo-Therapie signifikant überlegen. Bei den beiden Gruppen mit einem oder mehr Therapieversagen in der Vorgeschichte war das Ansprechen auf die 120-mg-Dosierung besser als auf die 240-mg-Dosierung. Nur in der Gruppe ohne vorheriges Therapieversagen war das Ansprechen auf die 240-mg-Dosierung besser. Die Ansprechraten auf Placebo waren durchweg in der Gruppe ohne Therapieversagen in der Vorgeschichte am höchsten und in der Gruppe mit mindestens 2 früheren Therapieversagen am niedrigsten.

Die randomisierte, doppelblinde, placebokontrollierte Phase-3b-FOCUS-Studie rekrutierte Patienten im Alter von 18 bis 70 Jahren mit episodischer oder chronischer Migräne mit dokumentiertem Scheitern von 2 bis 4 Klassen von Medikamenten zur Migräneprophylaxe in den letzten 10 Jahren. Die Patienten erhielten einmalig Fremanezumab (Monat 1: 675 mg; Monate 2 und 3: Placebo), monatliches Fremanezumab (Monat 1: $225 \mathrm{mg}$ bei episodischer Migräne und 675 mg bei chronischer Migräne; Monate 2 und 3: $225 \mathrm{mg}$ in beiden Migränesubgruppen) oder Placebo für 12 Wochen. Der primäre Endpunkt war die mittlere Reduktion der monatlichen Anzahl der Migränetage während der 12-wöchigen Behandlungszeit. Zwischen November 2017 und Juli 2018 wurden 838 Teilnehmer mit episodischer (329=39\%) oder mit chronischer Migräne (509=61\%) eingeschlossen. Die Reduktion der monatlichen Migränetage über 12 Wochen war für Fremanezumab höher als bei Placebo. Die Reduktion betrug -0,6 Tage für Placebo, -3,7 Tage für vierteljährliches Fremanezumab (Differenz vs. Placebo $-3-1$ [95\%-Cl= $-3,8$ bis $-2,4] ; p<0,0001)$ und $-4,1$ mit monatlichem Fremanezumab (Differenz vs. Placebo $-3-5$ [95\%-Cl= -4-2 bis $-2-8] ; \mathrm{p}<0,0001)$. 
Aufgrund der bislang vorliegenden Subgruppenanalysen ist die Behandlung mit Erenumab, Fremanezumab und Galcanezumab auch bei Patienten mit bislang therapieresistenter chronischer Migräne mit und ohne begleitenden Medikamentenübergebrauch zu empfehlen.

\section{Einsetzen der Wirkung}

Für alle 4 monoklonalen Antikörper wurde ein frühes Einsetzen der Wirkung gezeigt. Dies stellt einen Vorteil gegenüber den bisher etablierten Prophylaktika dar, bei denen die Wirkung auch rasch einsetzen kann, aber meist einige Wochen der langsamen Auftitrierung notwendig sind und die erste Wirksamkeitsbeurteilung meist erst 8-12 Wochen nach Erreichen einer tolerablen Zieldosis erfolgt. Ein Auftitrieren ist bei keinem der Antikörper notwendig. Es kann auch direkt mit einer höheren Loading Dose (Galcanezumab $2 \times 120 \mathrm{mg}$ ) oder einer höheren Dosis Erenumab (140 mg) sowie der 675-mg-Dosis Fremanezumab bei Gabe in 3 Monatsintervallen ein Therapiebeginn erfolgen. Der frühe Wirkeintritt von Erenumab wurde in einer Studie untersucht, die die Daten für chronische und episodische Migräne analysierte [42]. Im Vergleich zu Placebo ließ sich der Wirkeintritt schon in der ersten Behandlungswoche belegen. Sowohl die 70-mg- als auch die 140-mg-Dosis waren sowohl bei episodischer als auch bei chronischer Migräne ab der 2 . Woche nach Behandlungsbeginn signifikant Placebo überlegen. Ein vergleichbares Bild zeigte sich bei den Patienten, die eine mindestens $50 \%$-Reduktion der Migränetage erreichten. In der ersten Woche nach Injektion war Erenumab 140 mg bereits signifikant bei der episodischen Migräne Placebo überlegen, nach 2 Wochen für beide Dosierungen. Bei der chronischen Migräne waren beide Dosierungen ab der ersten Woche signifikant Placebo überlegen.

Für Fremanezumab belegt eine Post-hoc-Analyse ebenfalls einen raschen Wirkeintritt bei chronischer Migräne [43]. Analysiert wurden die Kopfschmerzstunden, die mit einem elektronischen Tagebuch erfasst wurden. Für die Gabe von 225 mg und 675 mg konnte eine statistische Überlegenheit gegenüber Placebo ab Tag 7 gezeigt werden.

Eine Post-hoc-Analyse konnte auch einen raschen Wirkungseintritt für Galcanezumab belegen [44]. Bereits in der ersten Behandlungswoche war Galcanezumab Placebo signifikant überlegen. Möglicherweise aufgrund der intravenösen Gabe konnte für Eptinezumab ein sehr früher Wirkeintritt gezeigt werden [37]. Die Post-hoc-Analyse der Studie zeigte eine gegenüber Placebo überlegene Wirkung bereits am Tag 1 nach der Gabe der Studienmedikation.

Zusammengefasst tritt bei allen monoklonalen Antikörpern die Wirkung rasch ein. Daher kann meist nach 8-12 Wochen entschieden werden, ob die Therapie wirksam ist oder nicht.

\section{Initiale Nonresponder}

In einer Post-hoc-Analyse wurde die Wirkung von Galcanezumab bei initialen Nonrespondern auf die Therapie analysiert [44]. Dabei zeigten Studienteilnehmer ohne Erreichen einer $50 \%$-Reduktion der monatlichen Migränetage im 1. Behandlungsmonat ein Ansprechen in Monat 2 und 3 häufiger als Studienteilnehmer unter Placebo, sodass die Behandlung über 3 Monate gerechtfertigt ist.

Betrachtet man die Studienergebnisse der bislang publizierten Arbeiten zum Ansprechen auf die monoklonalen Antikörper gegen
CGRP oder den CGRP-Rezeptor, so scheint die chronische Migräne etwas später anzusprechen als die episodische Migräne. Insgesamt rechtfertigen die Daten zu allen Antikörpern einen Therapieversuch über 3 Monate, auch wenn häufig schon ein sehr frühes Ansprechen gezeigt werden konnte.

\section{Weitere Zielparameter}

Neben dem Zielparameter > 50\%-Responder konnten in allen Zulassungsstudien auch signifikante Ergebnisse für die Reduktion der Zahl der Einnahmetage für Akutmedikation und für die Beeinträchtigung der Lebensqualität aufgrund der Migräne nachgewiesen werden. Diese Aspekte sollten in die Beurteilung der Wirksamkeit der Therapie einbezogen werden.

\section{Dosisintervall (1 versus 3 Monate)}

Erenumab wird im Abstand von 4 Wochen, Galcanezumab im monatlichen Abstand subkutan injiziert. Für Fremanezumab besteht die Möglichkeit einer monatlichen und einer 3-monatigen Gabe, wobei monatlich die Gabe von 225 mg oder alle 3 Monate die Gabe von 625 mg erfolgen kann. Ein signifikanter Unterschied zwischen der monatlichen und der 3-monatigen Gabe existiert nicht, wobei sich ein leichter Trend für eine bessere Wirksamkeit für das kürzere Therapieintervall zeigte. Eine 3-monatige Behandlung wird bei Frauen im gebärfähigen Alter ohne ausreichende Kontrazeption nicht empfohlen.

\section{Kombinationstherapie}

Die Evidenz für einen positiven Effekt einer Kombinationstherapie mit anderen prophylaktischen Medikamenten sowohl für die episodische (EM) als auch für die chronische Migräne (CM) schöpft sich derzeitig aus einer Post-hoc-Analyse aus gepoolten Daten von 2 Studien mit Fremanezumab [45]. In beiden Studien wurde Fremanezumab oder Placebo s. c. alle 28 Tage für 3 Monate verabreicht. In beiden Studienarmen verwendeten die Patienten ihre (zumindest seit 3 Monaten eingenommenen) prophylaktischen Medikationen. Diese umfassten Betablocker, Calciumkanalblocker, Antikonvulsiva, Candesartan, trizyklische Antidepressiva, Venlafaxin, Mirtazapin, Triptane, Opioide und nicht steroidale Antirheumatika (wenn diese täglich als Prophylaxe eingenommen wurden). Kopfschmerzcharakteristika wurden 28 Tage vor der ersten Gabe von Fremanezumab (Screening-Phase) und in den 3 Behandlungszyklen elektronisch aufgezeichnet. Primär analysiert wurde die Reduktion zumindest mittelstarker Kopfschmerzen betreffend Migränetagen und Anzahl von Kopfschmerztagen pro Behandlungszyklus. Sekundärer Endparameter war die Anzahl verwendeter Akutmedikation in jedem Behandlungsarm und Behandlungszyklus. Es wurden 133 Patienten (66 mit Placebo, 67 mit einem Prophylaktikum) in die Analyse einbezogen. In der mit Fremanezumab behandelten Patientengruppe verringerten sich die durchschnittlichen Migränetage/Monat von 14,6 auf 10,5 (-4,12) und in der Placebo-Gruppe von 14,6 auf $12,1(-2,47)(p=0,0321)$. Mittelstarke bis starke Migränetage (12,3 vs. 11,7$)$ verringerten sich ebenfalls statistisch signifikant in der Verum-Gruppe gegenüber der Placebo-Gruppe $(-4,16$ vs. $-2,37 ; p=0,0058)$. Die Tage, an denen eine zusätzliche Akutmedikation eingenommen werden musste, konnte in der mit Fremanezumab behandelten Patientengruppe statistisch signifikant reduziert werden $(-3,88$ vs. $-2,52 ; p=0,0414)$. Eine zumin- 
dest 50-\%-Reduktion der Migränetage wurde in $40 \%$ der Patienten in der Verum-Gruppe erzielt (vs. $24 \%$ in der Placebo-Gruppe). Die Nebenwirkungsrate war niedrig, dosis- und medikationsunspezifisch. Die Autoren schlossen aus diesen Ergebnissen, dass Fremanezumab als Add-on-Therapie gegenüber Placebo statistisch signifikant die Anzahl der Migräne- und Kopfschmerztage senkt und im klinischen Alltag die Kombination zu erwägen ist, insbesondere da keine Interaktionen zwischen CGRP-Antikörper und anderen Migräneprophylaktika zu erwarten sind. Bei Einleitung der Behandlung mit Fremanezumab kann die Therapie mit einem Arzneimittel zur Migräneprävention begleitend fortgeführt werden, sofern es vom Verordnenden für notwendig erachtet wird.

\section{Reduktion der Einnahme von Akutmedikation}

In allen randomisierten Studien wurden die Tage erfasst, an denen Akutmedikation eingenommen wurde. Diese waren naturgemäß bei der chronischen Migräne höher als bei der episodischen Migräne. Die Tabelle zeigt eine Reduktion der Tage mit Einnahme von Medikamenten zur Therapie von akuten Migräneattacken unter Placebo von $+0,5$ bis $-3,1$ und unter aktiver Therapie von $-1,1$ bis $-4,9$. Es bestehen, obwohl ein direkter Vergleich nicht möglich ist, keine Unterschiede zwischen Erenumab, Fremanezumab und Galcanezumab.

\section{Dauer der Therapie}

Fast alle Studien zur Wirksamkeit der monoklonalen Antikörper in der Migräneprophylaxe wurden über 3 Monate durchgeführt. Nur wenige Studien hatten eine Studiendauer von 6 Monaten. Nach der doppelblinden Studienperiode konnten die Patienten in eine offene Langzeitstudie wechseln.

Die Therapie sollte daher zunächst für 3 Monate erfolgen. Wenn kein befriedigender Therapieeffekt besteht, wird die Therapie beendet. Eine Therapie mit monoklonalen Antikörpern sollte nach 9-12 Monaten unterbrochen werden, um zu überprüfen, ob sie noch notwendig ist.

In den beiden EVOLVE-Studien wurde der Verlauf der Migräne am Ende der 6-monatigen doppelblinden Behandlungsphase über weitere 4 Monate untersucht [47]. Im Monat 6 hatte die Zahl der Migränetage im Monat um 4,5-5 Tage abgenommen. 4 Monate nach Absetzen verschlechterte sich die Migräne wieder. Die Reduktion der Migränetage betrug aber immer noch 3,5-4,1 Tage im Vergleich zur Baseline. Eine weitere Analyse bei Patienten, die Erenumab und Galcanezumab zum Ende der offenen Langzeitstudien absetzten, ergab auch hier, dass es zwar ab Woche 5 wieder zu einer Zunahme der monatlichen Migränetage kommen kann, diese aber die Ausgangswerte nicht erreicht [48].

\section{Sicherheit und Verträglichkeit}

Grundsätzlich sind wenige behandlungsabhängige Nebenwirkungen bei der Einnahme von monoklonalen CGRP-Antikörpern über einen Anwendungszeitraum von einem Jahr zu beobachten. Die Nebenwirkungen der CGRP-Antikörper sind zum allergrößten Teil milder Intensität und können ebenso nicht dem ZNS zugeordnet werden. Letzteres trägt signifikant zur Akzeptanz der Substanzen bei. Es muss festgehalten werden, dass in den Studien vor allem ansonsten gesunde Migränepatienten behandelt wurden. Es gibt kaum Vorerfahrungen bei Patienten mit zusätzlichen anderen Erkrankun-
- Tab. 22 Reduktion der Tage mit Einnahme von Medikamenten zur Therapie akuter Migräneattacke pro Monat

\begin{tabular}{|l|l|l|l|l|}
\hline Substanz & Studie & Placebo & Therapie 1 & Therapie 2 \\
\hline \multirow{2}{*}{ Erenumab } & EM (17) & $-0,2$ & $70 \mathrm{mg}-1,1$ & $140 \mathrm{mg}-1,6$ \\
\hline & EM (18) & $-0,6$ & $70 \mathrm{mg}-1,2$ & \\
\hline & EM (20) & $+0,5$ & $70 \mathrm{mg}-1,3$ & \\
\hline & CM (34) & $-1,6$ & $70 \mathrm{mg}-3,5$ & \\
\hline Fremanezumab & EM (46) & $-3,1$ & $225 \mathrm{mg}-4,9$ & $675 \mathrm{mg}-4,8$ \\
\hline & EM (21) & $-1,6$ & $225 \mathrm{mg}-2,9$ & $675 \mathrm{mg}-3,0$ \\
\hline & CM (35) & $-1,9$ & $675 \mathrm{mg}-3,7$ & $675 / 225 \mathrm{mg}$ \\
\hline & & & & $-4,2$ \\
\hline Galcanezumab & EM (22) & $-2,2$ & $120 \mathrm{mg}-4,0$ & $240 \mathrm{mg}-3,8$ \\
\hline & EM (23) & $-1,9$ & $120 \mathrm{mg}-3,7$ & $240 \mathrm{mg}-3,6$ \\
\hline & CM (36) & $-2,2$ & $120 \mathrm{mg}-4,7$ & $240 \mathrm{mg}-4,3$ \\
\hline & & & & \\
\hline
\end{tabular}

gen und das beobachtete Nebenwirkungsspektrum bezieht sich also im Wesentlichen auf ansonsten gesunde Migränepatienten.

Die häufigsten Nebenwirkungen des CGRP-Rezeptorantagonisten Erenumab sind über alle Studien hinweg Nasopharyngitis und Infektionen der oberen Atemwege, die beide gleich häufig wie bei der Gabe von Placebo waren [17, 20, 34]. Es finden sich bei Placebo und aktiver Substanz vor allem lokale Schmerzen, Reaktionen an der Einstichstelle und Juckreiz bei etwa $2 \%$ der Patienten. Allergische Nebenwirkungen (Anaphylaxie) werden selten gesehen. Etwas häufiger wurde in der STRIVE-Studie bei der 140-mg-Dosierung Obstipation beobachtet (3,4\%) als bei Gabe von $70 \mathrm{mg}(1,6 \%)$ bzw. 1,3\% nach Placebo [17]. Diese Beobachtung wurde jedoch nicht konsistent über alle Erenumab-Studien beobachtet [20, 34]. Muskelspasmen werden bei 2 \% der Patienten nach Gabe von Erenumab beobachtet [17]. Die amerikanische Zulassungsbehörde (FDA) weist darauf hin, dass nach Zulassung von Erenumab in den USA vereinzelt Fälle einer schweren Obstipation z.T mit Notwendigkeit eines operativen Eingriffs beobachtet wurden.

ZNS-Nebenwirkungen traten selten und nicht häufiger als unter Placebo auf. Dies ist ein weiteres Indiz dafür, dass die monoklonalen Antikörper nicht die Blut-Hirn-Schranke überqueren und nicht direkt im ZNS aktiv werden. Schwere unerwünschte Ereignisse traten mit maximal 3 \% in der Erenumab-70-mg-Gruppe bei CM-Patienten am häufigsten auf, jedoch waren diese nicht signifikant häufiger als bei Placebo und in der Regel nicht im kausalen Zusammenhang zur Erenumab-Gabe. Auch bei der Anwendung von Erenumab über ein Jahr waren Nebenwirkungen nicht häufiger als in den doppelblinden Studienphasen [49]. Für Erenumab sind 4 kardiovaskuläre Ereignisse berichtet. Alle Ereignisse waren durch vorbestehende schwere koronare Herzkrankheit $(n=2)$, Substanzabusus $(n=1)$ bzw. genetische Prädisposition ( $n=1$ ) erklärbar. Relevant sind bei allen monoklonalen Antikörpern Obstipationen, die selten schwerwiegend sein können.

Für Galcanezumab zeigen sich in geringerem Maße behandlungsabhängige Nebenwirkungen im Vergleich zu Placebo [22, 23, 43]. Hierbei berichten bis zu etwa $15 \%$ der Patienten Schmerzen oder lokale Reaktionen an der Injektionsstelle (Juckreiz/Erythem/ Schwellung), was etwas häufiger ist als bei Placebo. Es werden Ob- 
stipation in 1-1,5\% und Schwindel in 0,7-1,2\% in der 120-mgbzw. 240-mg-Dosis beobachtet. Diese sind numerisch häufiger als unter Placebo. Die Standarddosierung ist die monatliche Gabe von $120 \mathrm{mg}$ Galcanezumab. Todesfälle wurden nicht berichtet und ebenso keine schwerwiegenden Nebenwirkungen, die auf Galcanezumab zurückzuführen sind.

Etwa 24-30\% der Patienten berichten nach Gabe von Fremanezumab über Schmerzen bei der Injektion und ebenso berichten etwas mehr Patienten nach der Gabe des Antikörpers in den Studien lokale Reaktionen an der Einstichstelle wie Erythem (bis zu 16\%) oder Induration (<17\%) als nach Placebo [21, 30, 50] . Die Ergebnisse für die monatliche und für die Quartalsgabe unterscheiden sich nicht. Numerisch häufiger waren Blasenentzündungen unter Fremanezumab-Gabe (3,4\% Quartalsdosis) vs. 1,4\% bei Placebo. In einer gepoolten Datenanalyse aller Verträglichkeitsdaten zeigte sich dieser Effekt nicht mehr [50]. Ein Suizid und ein weiterer Todesfall bei einem Patienten mit chronisch obstruktiver Lungenerkrankung wurden in den Fremanezumab-Studiengruppen beobachtet.

Alle Sicherheitsdaten stützen sich auf Untersuchungen von jeweils über 2500 behandelten Patienten. Mit Erenumab wurden zudem 1300 Patienten über mindestens 1 Jahr behandelt, 279 Patienten wurden mit Galcanezumab und 1400 mit Fremanezumab über die Dauer eines Jahres therapiert. Patienten über 65 Jahren waren in den Studien mit Erenumab und Galcanezumab ausgeschlossen und nur $2 \%$ der Patienten mit Fremanezumab waren über 65 Jahre alt, sodass für diese Patientengruppe keine Aussagen zu Nebenwirkungen getroffen werden können, ebenso waren Minderjährige von den Studien ausgeschlossen. Patienten mit relevanten Vorerkrankungen waren in den Studien nicht eingeschlossen, sodass diesbezüglich zu besonderer Vorsicht gemahnt wird.

\section{Gegenanzeigen und Warnhinweise}

In den Phase-2- und -3-Studien waren Patienten mit akuten oder schweren kardiovaskulären Erkrankungen sowie Autoimmunerkrankungen ausgeschlossen. Bei diesen Patienten sollte ein CGRP-Antikörper oder CGRP-Rezeptorantikörper nur im begründeten Einzelfall vom Experten verordnet werden, da keine Sicherheitsdaten vorliegen.

Als einziger Antikörper wurde Erenumab in einer Dosierung von $140 \mathrm{mg}$ i. v. bei Patienten mit stabiler Angina pectoris bei schweren kardiovaskulären Erkrankungen mittels Ergometer-Test untersucht [17]. Hier zeigte sich kein Unterschied zu Placebo bei allen Zielparametern zur Placebo-Gabe. Weder die Zeit bis zur Senkung der ST-Strecke noch die Zeit bis zum Auftreten von Angina-Pectoris-Beschwerden noch die Zeit bis zum Abbruch des Ergometer-Tests waren durch die Erenumab-Gabe beeinträchtigt. Für die direkten CGRP-Antikörper liegen bisher leider keine vergleichbaren Untersuchungen vor. Weiterhin sollten Antikörper gegen CGRP oder den CGRP-Rezeptor vorsichtshalber nicht eingesetzt werden bei Patienten mit symptomatischer koronarer Herzerkrankung, ischämischem Insult, Subarachnoidalblutung, peripherer arterieller Verschlusskrankheit, COPD, pulmonaler Hypertension, M. Raynaud oder Transplantationsempfängern.

Monoklonale Antikörper gegen CGRP oder den CGRP-Rezeptor dürfen nicht in der Schwangerschaft und Stillzeit angewandt werden. Sie können die Plazenta ab Tag 90 über einen aktiven Transportmechanismus überqueren und sollen daher auf jeden Fall bei
Eintritt einer Schwangerschaft abgesetzt werden. Grundsätzlich sollen Frauen im gebärfähigen Alter eine Kontrazeption betreiben. Eine Wechselwirkung mit Kontrazeptiva ist für Erenumab untersucht und nicht bekannt. Eine Wechselwirkung mit anderen Antikörpern und immunologisch wirksamen Medikamenten ist für die monoklonalen Antikörper nicht bekannt.

Für Kinder und Jugendliche gibt es bisher keine Informationen zu Verträglichkeit und Sicherheit. MOAB sollten zudem bis auf Weiteres nicht bei Patienten mit entzündlichen Darmerkrankungen oder Wundheilungsstörungen eingesetzt werden.

\section{Redaktionskomitee}

\section{Hans-Christoph Diener}

Medizinische Fakultät der Universität Duisburg-Essen Institut für Medizinische Informatik, Biometrie und Epidemiologie (IMIBE) Hufelandstr. 26, 45147 Essen

\section{Stephanie Förderreuther Katharina Kamm \\ Neurologische Klinik, Ludwig-Maximilians-Universität München Klinikum Großhadern, Marchioninistr. 15, 81377 MünchenCharly Gaul Migräne- und Kopfschmerzklinik Königstein \\ Ölmühlweg 31, 61462 Königstein im Taunus}

\section{Florian Giese}

Klinik und Poliklinik für Neurologie, Universitätsklinikum Halle Gütchenstr. 14, 06108 Halle

\section{Till Hamann}

Tim P. Jürgens

Klinik und Poliklinik für Neurologie und Kopfschmerzzentrum Nord-Ost,

Universitätsmedizin Rostock, Gehlsheimer Str. 20, 18147 Rostock

\section{Dagny Holle-Lee}

Klinik für Neurologie und Westdeutsches Kopfschmerzzentrum Universitätsklinikum Essen, Hufelandstr. 55, 45147 Essen

\section{Torsten Kraya}

Klinik für Neurologie, Klinikum St. Georg Leipzig

Delitzscher Str. 141, 04129 Leipzig

\section{Christian Lampl}

Akutgeriatrie und Remobilisation, Kopfschmerzzentrum Seilerstätte Ordensklinikum Linz Barmherzige Schwestern, Seilerstätte 4, A-4010 Linz

\section{Arne May}

Institut für Systemische Neurowissenschaften, Universitätsklinikum Hamburg-Eppendorf (UKE), Gebäude W34, 3. Stock, Martinistraße 52, 20246 Hamburg

\section{Uwe Reuter}

Kopfschmerzzentrum, Charité Universitätsmedizin Berlin Charitéplatz 1, 10117 Berlin

\section{Armin Scheffler}

Klinik für Neurologie, Universitätsklinikum Essen, Hufelandstr. 55, 45147 Essen

\section{Peer Tfelt-Hansen}

Danish Headache Center, Rigshospitalet-Glostrup Hospital, University Hospital of Copenhagen, Department of Neurology, Glostrup Hospital, Ringvejen, DK-2600, Glostrup, Denmark 


\section{Federführende Autoren}

\section{Hans-Christoph Diener}

Medizinische Fakultät der Universität Duisburg-Essen Institut für Medizinische Informatik, Biometrie und Epidemiologie (IMIBE)

Hufelandstr. 26, 45147 Essen

\section{Arne May}

Institut für Systemische Neurowissenschaften, Universitätsklinikum Hamburg-Eppendorf (UKE), Gebäude W34, 3. Stock, Martinistraße 52, 20246 Hamburg

Entwicklungsstufe der Leitlinie: S1

\section{Leitlinienreport}

Bei dem Text handelt es sich um eine Ergänzung der bestehenden DGN-DMKG-Leitlinie: Therapie der Migräneattacke und Prophylaxe der Migräne (AWMF-Registernummer 030/057).

Geltungsbereich und Zweck

Begründung für die Auswahl des Leitlinienthemas

Seit Kurzem stehen 3 monoklonale Antikörper gegen CGRP und den CGRP-Rezeptor zur medikamentösen Prophylaxe der Migräne zur Verfügung. Ein weiterer (Eptinezumab) wird in absehbarer Zeit zugelassen. Daher musste die bestehende Leitlinie zur Therapie der Migräneattacke und Prophylaxe der Migräne der DGN und der DMKG aktualisiert werden.

Zielorientierung der Leitlinie

Die Leitlinie befasst sich mit dem therapeutischen Einsatz von Antikörpern gegen CGRP oder den CGRP-Rezeptor zur Prophylaxe der episodischen oder chronischen Migräne.

Patientenzielgruppe

Patienten mit Migräne, bei denen die bisherigen medikamentösen Therapien unwirksam waren, nicht vertragen wurden oder kontraindiziert sind.

Versorgungsbereich

Der Anwendungsbereich der Leitlinie umfasst die ambulante, tagesklinische und stationäre Versorgung.

Anwender Zielgruppe/Adressaten

Die Empfehlung der Leitlinie richtet sich an Neurologen und Schmerztherapeuten, die Patienten mit therapierefraktärer Migräne behandeln.

\section{Zusammensetzung der Leitliniengruppe}

Siehe Redaktionskomitee S. 21
Methoden

Recherchen, Auswahl bewährter wissenschaftlicher Belege

Zunächst wurden 7 Fragen zum Einsatz von monoklonalen Antikörpern gegen CGRP oder den CGRP-Rezeptor formuliert und für diese Fragen eine systematische Literaturrecherche durchgeführt. Diese erfolgte mit den Begriffen CGRP, CGRP antibody, monoclonal antibody against CGRP, CGRP-receptor antagonist, Erenumab, Fremanezumab, Galcanezumab, Eptinezumab, episodic migraine, chronic migraine, safety, tolerability, adverse events, medication overuse headache. Die Literaturrecherche umfasste den Zeitraum bis Mitte August 2019.

Auswahl der Evidenz

Die relevante Literatur wurde von den Autoren ausgewählt, die den jeweiligen Abschnitt der Leitlinie formulierten.

Erstellung der Leitlinie und Formulierung der Empfehlungen

Die beiden Koordinatoren verfassten die Leitlinie unter Mitarbeit von Peer Tfelt-Hansen (Methodiker).

Die übrigen Mitwirkenden waren bei der Literaturrecherche eingebunden und haben den Text der Leitlinie in mehreren schriftlichen Delphi-Runden korrigiert und verabschiedet.

Externe Begutachtung

Die externe Begutachtung erfolgte durch 3 Mitglieder der DGN-Leitlinienkommission sowie zusätzlich durch zwei unabhängige externe Reviewer der DGN. Die Leitlinie wurde vom Vorstand der DMKG verabschiedet.

\section{Redaktionelle Unabhängigkeit}

Finanzierung der Leitlinie

Es erfolgte keine externe Finanzierung der Leitlinie. Alle Mitwirkenden haben ehrenamtlich an dieser Leitlinie mitgewirkt.

Erklärung von Interessen und Umgang mit Interessenkonflikten

Alle Mitwirkenden an der Leitlinie haben ihre Interessenerklärungen (AWMF-Formular zur Erklärung von Interessen im Rahmen von Leitlinienvorhaben) rechtzeitig und vollständig ausgefüllt beim Koordinator bzw. beim Editorial Office Leitlinien der DGN eingereicht. Im Formblatt wurden die Ausfüllenden gebeten, bei den dargelegten Interessen mit anzugeben, ob ein thematischer Bezug zur Leitlinie/zum Leitlinienthema besteht. Bei unvollständigen Angaben wurde Nachbesserung eingefordert. Abgefragt wurde auch die Höhe der Bezüge, die jedoch nicht veröffentlicht wird. Eine Selbsteinschätzung fand nicht mehr statt.

Alle Interessenerklärungen wurden durch einen anonym arbeitenden, unabhängigen und sachkundigen Interessenkonfliktbeauftragten der DGN auf potenzielle thematisch relevante Interessen begutachtet.

Die Angaben wurden im Hinblick auf einen vorliegenden thematischen Bezug, auf thematische Relevanz, Art und Intensität der Beziehung sowie auf die absolute Höhe der Bezüge geprüft.

Folgende Bewertungskriterien wurden zugrunde gelegt:

- bezahlte Gutachter-/Beratertätigkeit für Industrieunternehmen

- Mitarbeit in einem wissenschaftlichen Beirat/Advisory Board: bezahlte Tätigkeit für Industrieunternehmen

- Vorträge: bezahlt durch die Industrie

- Autoren- oder Koautorenschaft: nur wenn industriegelenkt

- Forschungsvorhaben/Durchführung klinischer Studien: direkt oder teilfinanziert von Industrieunternehmen

- Eigentümerinteressen (Patente, Aktienbesitz) mit Leitlinien-Bezug

- indirekte Interessen mit Relevanz 


\section{0-\%-Regel der DGN}

Eine spezielle Vorgabe der DGN seit Mai 2014 sieht vor, dass für eine ausgewogene Zusammensetzung der Leitliniengruppe mindestens $50 \%$ der an der Leitlinie Beteiligten keine oder nur geringe für die Leitlinie relevante Interessenkonflikte haben dürfen. Die DGN hat sich zur Einführung der 50-\%-Regel entschieden, weil damit bei Abstimmungen kein Überhang von Partikularinteressen entstehen kann.

\section{Bewertung der dargelegten Interessen}

Das Redaktionskomitee umfasst 14 Mitglieder, davon 2 federführende Autoren. Von der Gesamtgruppe sind 9 Mitglieder frei von Interessenkonflikten oder besitzen lediglich geringe thematisch relevante Interessenkonflikte. 5 Mitwirkende mit moderaten Interessenkonflikten waren an der Formulierung des Leitlinientextes nicht beteiligt. Sie hatten beratende und/oder korrigierende Funktion inne.

Die $50 \%$-Regel der DGN wurde eingehalten.

Die dargelegten Interessen der Beteiligten sowie deren Bewertung durch Interessenkonfliktbeauftragte der DGN sind aus Gründen der Transparenz in der tabellarischen Zusammenfassung (siehe separates Dokument) aufgeführt.

\section{Verbreitung und Implementierung}

Die Leitlinie wird über die Homepage der DGN, DMKG und der AWMF veröffentlicht. Gleichzeitig erfolgt die Veröffentlichung in der Zeitschrift Nervenheilkunde und der Arzneimitteltherapie.

\section{Literatur}

[1] American Headache Society. The American Headache Society Position Statement On Integrating New Migraine Treatments Into Clinical Practice. Headache 2019; 59(1): 1-18

[2] Kosinski M, Bayliss MS, Bjorner JB, et al. A six-item short-form survey for measuring headache impact: the HIT-6. Qual Life Res 2003; 12(8): $963-74$

[3] Diener H-C, Gaul C, Kropp P, et al. Therapie der Migräneattacke und Prophylaxe der Migräne, S1-Leitlinie [https://www.dgn.org/leitlinien]. Deutsche Gesellschaft für Neurologie; Berlin 2018

[4] Tassorelli C, Diener HC, Dodick DW, et al. Guidelines of the International Headache Society for controlled trials of preventive treatment of chronic migraine in adults. Cephalalgia 2018: 333102418758283

[5] Berger A, Bloudek LM, Varon SF, et al. Adherence with migraine prophylaxis in clinical practice. Pain Pract 2012; 12(7): 541-9

[6] Goadsby PJ, Edvinsson L. Sumatriptan reverses the changes in calcitonin gene-related peptide seen in the headache phase of migraine. Cephalalgia 1991; 11 Suppl 11: 3-4

[7] Goadsby PJ, Edvinsson L. The trigeminovascular system and migraine: studies characterizing cerebrovascular and neuropeptide changes seen in humans and cats. Ann Neurol 1993; 33(1): 48-56

[8] Eftekhari S, Salvatore CA, Calamari A, et al. Differential distribution of calcitonin gene-related peptide and its receptor components in the human trigeminal ganglion. Neuroscience 2010; 169(2): 683-96

[9] Edvinsson L, Villalon CM, Maassen Van Den Brink A. Basic mechanisms of migraine and its acute treatment. Pharmacol Ther 2012; 136(3): 319-33
[10] Edvinsson L, Goadsby P], Olesen IL, et al. CGRP, CGRP mRNA and CGRP1 receptor mRNA and release from the human trigeminovascular system. In: Poyner D, Marshall I, Brain S, editors. The CGRP Family: Calcitonin Gene-Related Peptide (CGRP), Amylin, and Adrenomedullin. Georgetown, Texas: Landes Bioscience; 2000, 167-71

[11] McCulloch J, Uddman R, Kingman TA, et al. Calcitonin gene-related peptide: functional role in cerebrovascular regulation. Proc Natl Acad Sci U S A 1986; 83(15): 5731-5

[12] Edvinsson L, Haanes KA, Warfvinge K, et al. CGRP as the target of new migraine therapies - successful translation from bench to clinic. Nat Rev Neurol 2018; 14(6): 338-50

[13] Olesen J, Diener HC, Husstedt IW, et al. Calcitonin gene-related peptide receptor antagonist BIBN 4096 BS for the acute treatment of migraine. The New England Journal of Medicine 2004; 350(11): 1104-10

[14] Charles A, Pozo-Rosich P. Targeting calcitonin gene-related peptide: a new era in migraine therapy. Lancet 2019; 394(10210): 1765-74

[15] Yuan H, Spare NM, Silberstein SD. Targeting CGRP for the Prevention of Migraine and Cluster Headache: A Narrative Review. Headache 2019; 59 Suppl 2: 20-32

[16] Diener H, Gaul C. Erenumab. Drug Report 2018; 12(19): 1-17

[17] Goadsby PJ, Reuter U, Hallstrom Y, et al. A Controlled Trial of Erenumab for Episodic Migraine. The New England Journal of Medicine 2017; 377(22): 2123-32

[18] Dodick DW, Ashina M, Brandes JL, et al. ARISE: A Phase 3 randomized trial of erenumab for episodic migraine. Cephalalgia 2018; 38(6): 1026-37

[19] Reuter U, Goadsby J, Lanteri-Minet M, et al. Efficacy and safety of erenumab in episodic migraine patients with 2-4 prior preventive treatment failures: results from the phase $3 \mathrm{~b}$ LIBERTY study. Migraine Trust International Symposium 2018; September, 2018

[20] Reuter U, Goadsby P], Lanteri-Minet M, et al. Efficacy and tolerability of erenumab in patients with episodic migraine in whom two-to-four previous preventive treatments were unsuccessful: a randomised, double-blind, placebo-controlled, phase 3b study. Lancet 2018; 392(10161): 2280-7

[21] Dodick DW, Silberstein SD, Bigal ME, et al. Effect of Fremanezumab Compared With Placebo for Prevention of Episodic Migraine: A Randomized Clinical Trial. Jama 2018; 319(19): 1999-2008

[22] Stauffer VL, Dodick DW, Zhang Q, et al. Evaluation of Galcanezumab for the Prevention of Episodic Migraine: The EVOLVE-1 Randomized Clinical Trial. JAMA Neurol 2018; 75(9): 1080-8

[23] Skljarevski V, Matharu M, Millen BA, et al. Efficacy and safety of galcanezumab for the prevention of episodic migraine: Results of the EVOLVE-2 Phase 3 randomized controlled clinical trial. Cephalalgia 2018; 38(8): 1442-54

[24] Rosen N, Pearlman E, Ruff D, et al. 100\% Response Rate to Galcanezumab in Patients With Episodic Migraine: A Post Hoc Analysis of the Results From Phase 3, Randomized, Double-Blind, Placebo-Controlled EVOLVE-1 and EVOLVE-2 Studies. Headache 2018; 58(9): 1347-57

[25] Tepper SJ. Anti-Calcitonin Gene-Related Peptide (CGRP) Therapies: Update on a Previous Review After the American Headache Society 60th Scientific Meeting, San Francisco, June 2018. Headache 2018; 58 Suppl 3: 276-90

[26] Aurora SK, Dodick DW, Turkel CC, et al. OnabotulinumtoxinA for treatment of chronic migraine: results from the double-blind, randomized, placebo-controlled phase of the PREEMPT 1 trial. Cephalalgia : an international journal of headache 2010; 30(7): 793-803

[27] Diener HC, Dodick DW, Aurora SK, et al. OnabotulinumtoxinA for treatment of chronic migraine: results from the double-blind, randomized, placebo-controlled phase of the PREEMPT 2 trial. Cephalalgia 2010; 30(7): 804-14 
[28] Dodick DW, Turkel CC, DeGryse RE, et al. OnabotulinumtoxinA for treatment of chronic migraine: pooled results from the double-blind, randomized, placebo-controlled phases of the PREEMPT clinical program. Headache 2010; 50(6): 921-36

[29] Silberstein SD, Blumenfeld AM, Cady RK, et al. OnabotulinumtoxinA for treatment of chronic migraine: PREEMPT 24-week pooled subgroup analysis of patients who had acute headache medication overuse at baseline. J Neurol Sci 2013; 331(1-2): 48-56

[30] Diener HC, Bussone G, Van Oene JC, et al. Topiramate reduces headache days in chronic migraine: a randomized, double-blind, placebo-controlled study. Cephalalgia 2007; 27(7): 814-23

[31] Diener HC, Dodick DW, Goadsby PJ, et al. Utility of topiramate for the treatment of patients with chronic migraine in the presence or absence of acute medication overuse. Cephalalgia 2009; 29(10): 1021-7

[32] Diener HC, Bussone G, Van Oene JC, et al. Topiramate reduces headache days in chronic migraine: a randomized, double-blind, placebo-controlled study. Cephalalgia 2007; 27(7): 814-23

[33] Silberstein S, Lipton R, Dodick D, et al. Topiramate treatment of chronic migraine: a randomized, placebo-controlled trial of quality of life and other efficacy measures. Headache 2009; 49(8): 1153-62

[34] Tepper S, Ashina M, Reuter U, et al. Safety and efficacy of erenumab for preventive treatment of chronic migraine: a randomised, double-blind, placebo-controlled phase 2 trial. The Lancet Neurology 2017; 16(6): 425-34

[35] Silberstein SD, Dodick DW, Bigal ME, et al. Fremanezumab for the Preventive Treatment of Chronic Migraine. The New England Journal of medicine 2017; 377(22): 2113-22

[36] Detke HC, Goadsby PJ, Wang S, et al. Galcanezumab in chronic migraine: The randomized, double-blind, placebo-controlled REGAIN study. Neurology 2018; 91(24): e2211-e21

[37] Dodick DW, Lipton RB, Silberstein S, et al. Eptinezumab for prevention of chronic migraine: A randomized phase $2 \mathrm{~b}$ clinical trial. Cephalalgia 2019; 39(9): 1075-85

[38] Ruff DD, Ford JH, Tockhorn-Heidenreich A, et al. Efficacy of galcanezumab in patients with chronic migraine and a history of preventive treatment failure. Cephalalgia 2019; 39(8): 931-44

[39] Sacco S, Bendtsen L, Ashina M, et al. European headache federation guideline on the use of monoclonal antibodies acting on the calcitonin gene related peptide or its receptor for migraine prevention. The Journal of Headache and Pain 2019; 20(1): 6
[40] Reuter U, Goadsby P], Lanteri-Minet M, et al. Efficacy and tolerability of erenumab in patients with episodic migraine in whom two-to-four previous preventive treatments were unsuccessful: a randomised, double-blind, placebo-controlled, phase 3b study. Lancet 2018; 392: 2280-2287

[41] Ashina M, Tepper S, Brandes JL, et al. Efficacy and safety of erenumab (AMG334) in chronic migraine patients with prior preventive treatment failure: A subgroup analysis of a randomized, double-blind, placebo-controlled study. Cephalalgia 2018; 38(10): 1611-21

[42] Schwedt T, Reuter U, Tepper S, et al. Early onset of efficacy with erenumab in patients with episodic and chronic migraine. The Journal of Headache and Pain 2018; 19(1): 92

[43] Bigal ME, Dodick DW, Krymchantowski AV, et al. TEV-48125 for the preventive treatment of chronic migraine: Efficacy at early time points. Neurology 2016; 87(1): 41-8

[44] Skljarevski V, Oakes TM, Zhang Q, et al. Effect of Different Doses of Galcanezumab vs Placebo for Episodic Migraine Prevention: A Randomized Clinical Trial. JAMA Neurol 2018; 75: 187-193

[45] Cohen JM, Dodick DW, Yang R, et al. Fremanezumab as Add-On Treatment for Patients Treated With Other Migraine Preventive Medicines. Headache 2017; 57(9): 1375-84

[46] Bigal ME, Dodick DW, Rapoport AM, et al. Safety, tolerability, and efficacy of TEV-48125 for preventive treatment of high-frequency episodic migraine: a multicentre, randomised, double-blind, placebo-controlled, phase 2b study. The Lancet Neurology 2015; 14(11): 1081-90

[47] Stauffer VL, Wang S, Voulgaropoulos M, et al. Effect of Galcanezumab Following Treatment Cessation in Patients With Migraine: Results From 2 Randomized Phase 3 Trials. Headache 2019; 59(6): 834-47

[48] Raffaelli B, Mussetto V, Israel $\mathrm{H}$, et al. Erenumab and galcanezumab in chronic migraine prevention: effects after treatment termination. The Journal of Headache and Pain 2019; 20(1): 66

[49] Ashina M, Dodick D, Goadsby PJ, et al. Erenumab (AMG 334) in episodic migraine: Interim analysis of an ongoing open-label study. Neurology 2017; 89(12): 1237-43

[50] Silberstein SD, McAllister P, Ning X, et al. Safety and Tolerability of Fremanezumab for the Prevention of Migraine: A Pooled Analysis of Phases $2 b$ and 3 Clinical Trials. Headache 2019; 59(6): 880-90

[51] Depre C, Antalik L, Starling A, et al. A Randomized, Double-Blind, Placebo-Controlled Study to Evaluate the Effect of Erenumab on Exercise Time During a Treadmill Test in Patients With Stable Angina. Headache 2018; 58(5): 715-23 